\title{
On Stopping Voluntary Muscle Relaxations and Contractions: Evidence for Shared Control Mechanisms and Muscle State-Specific Active Breaking
}

\author{
Jack De Havas, Sho Ito, and Hiroaki Gomi \\ NTT Communication Science Laboratories, Nippon Telegraph and Telephone Corporation, Atsugi 243-0198, Kanagawa, Japan
}

Control of the body requires inhibiting complex actions, involving contracting and relaxing muscles. However, little is known of how voluntary commands to relax a muscle are cancelled. Action inhibition causes both suppression of muscle activity and the transient excitation of antagonist muscles, the latter being termed active breaking. We hypothesized that active breaking is present when stopping muscle relaxations. Stop signal experiments were used to compare the mechanisms of active breaking for muscle relaxations and contractions in male and female human participants. In experiments 1 and 2, go signals were presented that required participants to contract or relax their biceps or triceps muscle. Infrequent Stop signals occurred after fixed delays (0-500 ms), requiring that participants cancelled go commands. In experiment 3, participants increased (contract) or decreased (relax) an existing isometric finger abduction depending on the go signal, and cancelled these force changes whenever Stop signals occurred (dynamically adjusted delay). We found that muscle relaxations were stopped rapidly, met predictions of existing race models, and had Stop signal reaction times that correlated with those observed during the stopping of muscle contractions, suggesting shared control mechanisms. However, stopped relaxations were preceded by transient increases in electromyography (EMG), while stopped contractions were preceded by decreases in EMG, suggesting a later divergence of control. Muscle state-specific active breaking occurred simultaneously across muscles, consistent with a central origin. Our results indicate that the later stages of action inhibition involve separate excitatory and inhibitory pathways, which act automatically to cancel complex body movements.

Key words: action inhibition; active breaking; movement; muscle relaxation; Stop signal; voluntary

Significance Statement

The mechanisms of how muscle relaxations are cancelled are poorly understood. We showed in three experiments involving multiple effectors that stopping muscle relaxations involves transient bursts of EMG activity, which resemble cocontraction and have onsets that correlate with Stop signal reaction time. Comparison with the stopping of matched muscle contractions showed that active breaking was muscle state specific, being positive for relaxations and negative for contractions. The two processes were also observed to co-occur in agonist-antagonist pairs, suggesting separate pathways. The rapid, automatic activation of both pathways may explain how complex actions can be stopped at any stage of their execution.

\section{Introduction}

Control of the body necessitates the rapid cancelling of actions in response to changes in the environment. Such actions often involve multiple muscles in different states of contraction and

Received Jan. 1, 2020; revised May 16, 2020; accepted June 19, 2020.

Author contributions: J.D.H., S.I., and H.G. designed research; J.D.H. and S.I. performed research; J.D.H. analyzed data; J.D.H. and H.G. wrote the paper.

This work was funded by a Japan Society for the Promotion of Science short-term fellowship. H.G. was further supported by Grants-in-Aid for Scientific Research (JP16H06566) from Japan Society for the Promotion of Science. We thank Maiko Goshima for help with providing illustrations for task design figures, and two anonymous reviewers for useful comments on the manuscript.

The authors declare no competing financial interests.

Correspondence should be addressed to Jack De Havas at jdehavas@gmail.com.

https://doi.org/10.1523/JNEUROSCI.0002-20.2020

Copyright $\odot 2020$ the authors relaxation. However, most action inhibition experiments have focused on simple button press responses and saccades (Band and van Boxtel, 1999; Verbruggen and Logan, 2008). Less is known about complex actions, particularly those caused by muscle relaxations.

Voluntary isometric and isotonic muscle relaxations are an active process (Toma et al., 2000; Alegre et al., 2003), vital for updating posture and initiating movement (Buccolieri et al., 2003). Relaxation commands activate the supplementary and primary motor cortex (M1) to a similar degree to matched muscle contractions (Toma et al., 1999; Spraker et al., 2009). Before a relaxation command, readiness potentials are observed at frontocentral electrodes (Dimitrov, 1985; Terada et al., 1995; Rothwell et al., 1998), while the execution of the movement itself is 
preceded by a lateralized readiness potential of equal amplitude and latency to those preceding muscle contractions (Pope et al., 2007). Understanding the control of voluntary muscle relaxations is important because muscle relaxation deficits are prevalent in stroke (Chae et al., 2002, 2006; Seo et al., 2009), dystonia (Yazawa et al., 1999; Oga et al., 2002), and Parkinson's disease (Kunesch et al., 1995; Grasso et al., 1996; Labyt et al., 2005).

Given the control similarities to muscle contraction, it should be possible to cancel a "go command" to relax a muscle if a "stop command" is issued early enough. The Stop signal task involves participants responding to a go signal on every trial and attempting to suppress their responses whenever an infrequent Stop signal occurs (Lappin and Eriksen, 1966; Logan et al., 1984). Stop signal reaction time (SSRT) can then be calculated, which is a good predictor of general inhibitory function (Logan et al., 1997; Williams et al., 1999). Stop and Go processes race to completion via largely separate pathways in the brain (Logan and Cowan, 1984; Aron et al., 2007). If stopping muscle relaxations conforms to this account, it may be possible to derive the general mechanisms determining how complex actions are cancelled.

Action inhibition involves multiple central and peripheral pathways. In the motor cortex, stopping is associated with increased short-interval intracortical inhibition (SICI; Coxon et al., 2006; van den Wildenberg et al., 2010), indicating greater inhibitory GABAergic activity. Increased SICI is also observed during muscle relaxation (Buccolieri et al., 2004; Motawar et al., 2012). As such, combining muscle relaxation go commands and action inhibition might produce slowing of SSRT due to interference. However, excitatory pathways likely also contribute to stopping, negating any such slowing. Excitation has been observed at the periphery in the form of bursts of antagonist activity when reaching movements are inhibited (Atsma et al., 2018). This "active breaking" may also explain how ballistic movements (McGarry and Franks, 1997) and increases of isometric force (de Jong et al., 1990) can be arrested midway through their execution. Nevertheless, it is unknown whether active breaking is confined to the antagonist muscle, whether it occurs uniformly in relaxing and contracting muscles, or whether it manifests differently in both as a form of muscle statespecific response. Relatedly, it is uncertain whether active breaking arises from changes at the agonist, which in turn influence the antagonist (peripheral command), or from a single central command, which may be similar to cocontraction.

We therefore designed a series of Stop signal experiments to determine the general peripheral mechanisms underpinning the inhibition of relaxing and contracting muscles. We test the following hypotheses: (1) that voluntary relaxations are cancelled as rapidly as muscle contractions, in accordance with the principles of the race model; (2) that active breaking is present across movement types, but manifests differently depending on the muscle state; and (3) that active breaking involves simultaneous action across muscles.

\section{Materials and Methods}

Equipment. Participants were seated at an adjustable table, fitted with foam padding. Modified Stop signal tasks were run via MATLAB (version 2017a) and Psychtoolbox (Brainard, 1997). Visual stimuli were displayed via a flat screen monitor $(27$ inch LCD, $1902 \times 1080$ pixels, $60 \mathrm{~Hz}$ refresh rate). Auditory stimuli consisted of tones delivered via a buzzer $(3000 \mathrm{~Hz}, 50 \mathrm{~dB}, 160 \mathrm{~ms})$.

Electromyography (EMG) was recorded from bipolar surface electrodes (Ag- $\mathrm{AgCl}$ disposable electrode, GE Healthcare Japan) placed over the middle of the right biceps brachii and right triceps brachii lateral head muscles in experiments 1 and 2, and on the first dorsal interosseous (FDI) muscle in experiment 3. EMG signals were sampled at $2000 \mathrm{~Hz}$ and amplified using variable gain (MME-3132, Nihon Kohden). For the purposes of training participants to relax their muscles, EMG data were displayed via an oscilloscope (TDS2004C, Tektronix) positioned at eye level in front of them. This was removed during the actual task.

In experiments 1 and 2, elbow angle was determined via the use of three infrared reflective markers positioned at the forearm, elbow, and shoulder of the right arm. Marker position was detected via two motiontracking cameras (Oqus300, Qualisys) with a sampling rate of $250 \mathrm{~Hz}$. In experiment 3 , isometric finger abduction force was measured using a force sensor (six-axis force sensor; ThinNANO 5/4-A, BL-Autotech). Maximum voluntary forces were recorded at the start of the experiment via a different force sensor (force gauge; FGC-5, Nidec-Shimpo).

Participants. For experiment 1, we recruited 13 participants (8 female; mean age $=34.5$ years; $S D=9.2$ years). Experiment 2 included 12 participants (8 female; mean age $=33.83$ years; $S D=9.42$ years), 5 of whom had previously participated in experiment 1 . We recruited 16 participants for experiment 3. However, two participants were excluded before the analysis phase due to equipment failure. This left 14 participants who were included in the analysis ( 11 female; mean age $=36.71$ years; $\mathrm{SD}=8.63$ years). Of these participants, five had participated in experiments 1 and three had participated in experiment 2. Experiments were undertaken with the understanding and written consent of each participant in accordance with the Code of Ethics of the World Medical Association (Declaration of Helsinki), and with the NTT Communication Science Laboratories Research Ethics Committee approval.

General procedure. Participants first completed a practice button press version of the Stop signal task, similar to those widely used in the Stop signal literature (Verbruggen et al., 2019). Maximum voluntary contractions (MVCs) of relevant muscles were then recorded via $5 \mathrm{~s}$ isometric contractions against a fixed surface. All experiments used a modified version of the Stop signal task. Participants maintained a constant level of muscle contraction in the target effector while looking at a fixation cross on a screen $70 \mathrm{~cm}$ in front of them. On every trial, a visual go signal was presented in the center of the screen in the form of a colored shape (subtending a $4.7^{\circ}$ visual angle). In the relaxation condition, participants relaxed the target muscle, and in the contraction condition, they contracted the target muscle as quickly as possible in response to the go signal. On a randomly selected subset of trials (30\%), a Stop signal (tone) was presented after a specifically controlled Stop signal delay (SSD). Experiments 1 and 2 compared the stopping of relaxation of the biceps to the stopping of contractions of the triceps and biceps muscle, respectively. Thus, in experiment 1, the movement direction was matched (elbow extension), and in experiment 2 the primary muscle was matched (biceps brachii) across movement conditions. Experiment 3 was conducted using isometric relaxations and contractions of the FDI muscle to determine whether the findings of the previous experiments generalized to other effectors.

Procedure for experiment 1 . The target muscle was the right biceps brachii in the relax condition and the triceps brachii in the contract condition. EMG was recorded from both muscles in all conditions. Uniquely in experiment 1 , we tested the relax and contract conditions in separate blocks (counterbalanced). Participants were informed of the block type on screen at the start of each block. They rested their elbow on a padded table, supinated, and bent at an angle of $\sim 30^{\circ}$ from the horizontal (Fig. 1A), which required activity in the biceps muscle $(\sim 4 \%$ MVC). Before each trial, arm angle was adjusted via visual feedback on screen. Successfully matching current to required elbow angle triggered the appearance of a fixation cross.

After a random interstimulus interval (ISI; $2-4 \mathrm{~s}$ ), the fixation cross was replaced by green shape subtending a $4.7^{\circ}$ of visual angle (Go/NoGo stimulus). Participants moved their right arm downward as rapidly as possible whenever a green circle appeared on the screen (Go trials; $80 \%$ of trials) and remained stationary whenever a green square appeared (No-Go trials; $20 \%$ of trials). No-Go trials ensured that the participants processed the Go stimulus before acting (Verbruggen and Logan, 2009) but were not analyzed further. During "relaxation blocks," participants moved their right arm downward (elbow extension) by 

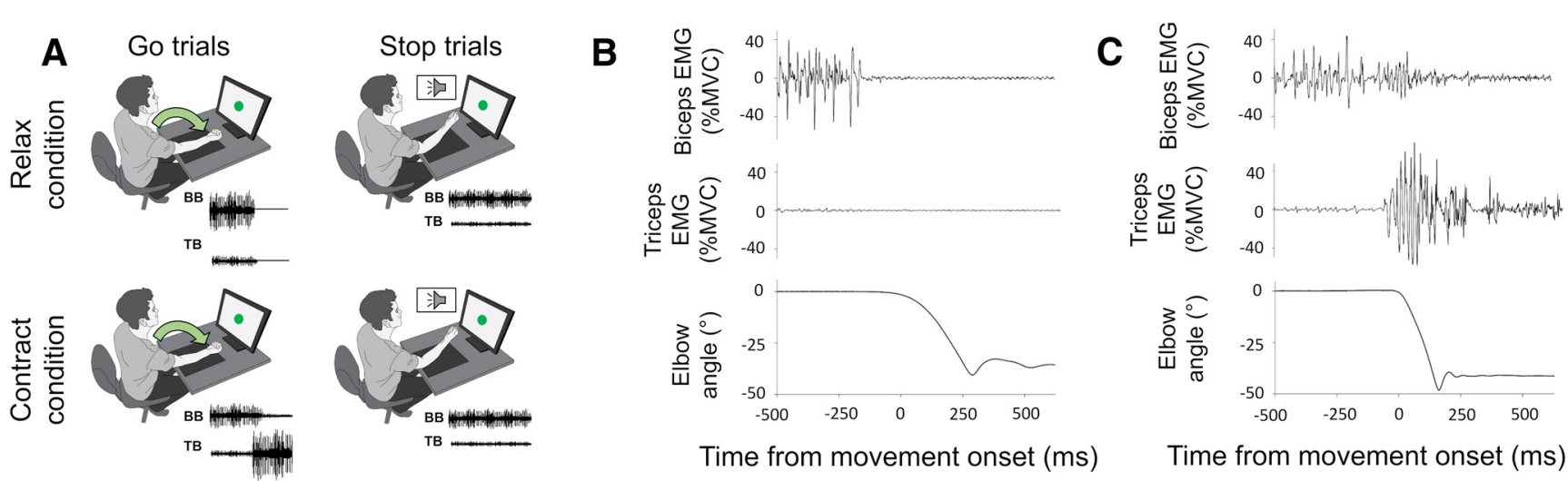

Time from movement onset (ms)

Time from movement onset (ms)
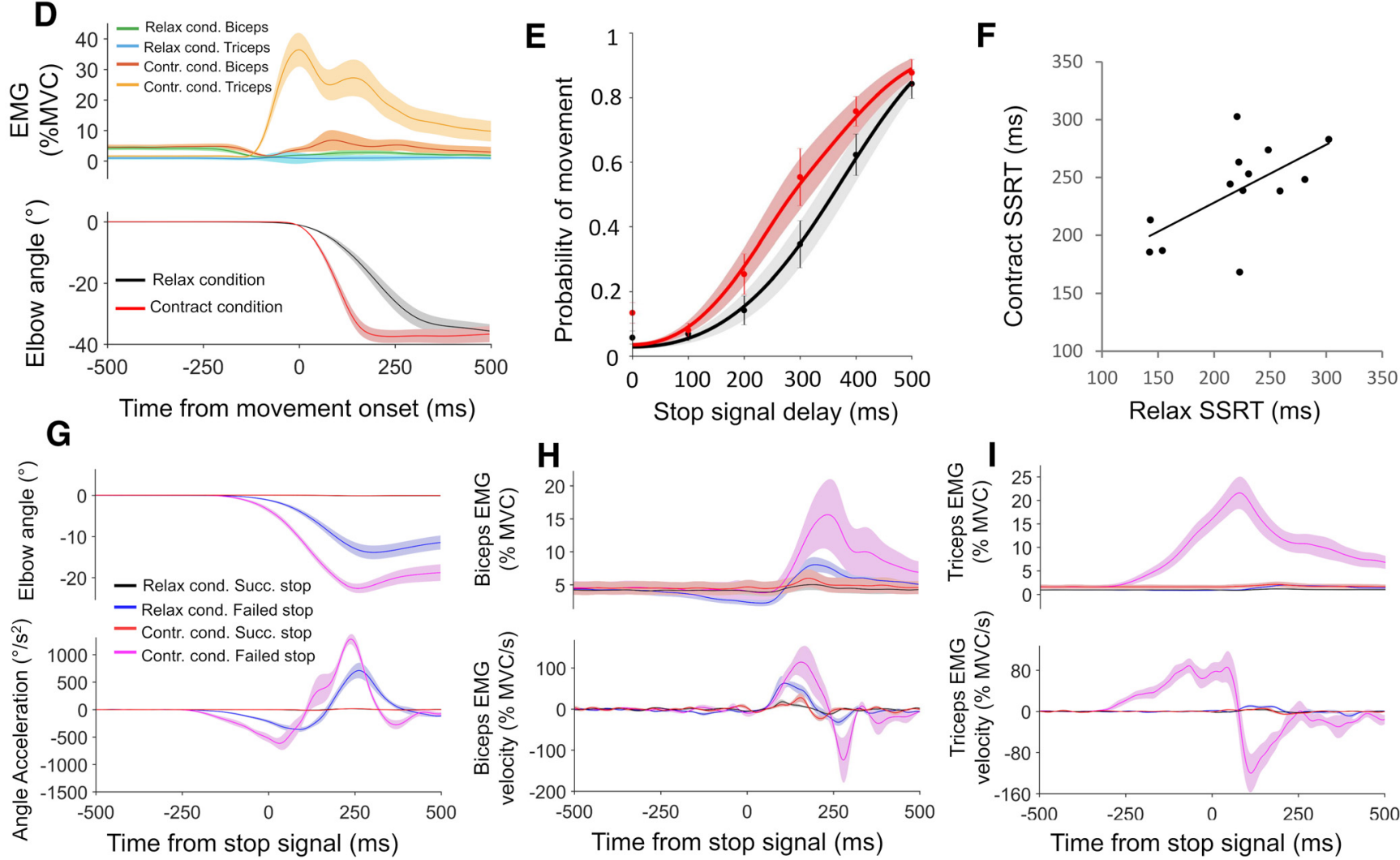

Figure 1. Design and results for experiment 1. $A$, Task setup is shown. In relax and contract blocks, participants made elbow extensions in response to Go signals and attempted to prevent these movements whenever a Stop signal occurred. $\boldsymbol{B}, \boldsymbol{C}$, Elbow extensions were driven by biceps relaxation or triceps activation, respectively, as shown in the representative $G 0$ trials from the relax $(\boldsymbol{B})$ and contract $(\boldsymbol{C})$ conditions. $\boldsymbol{D}$, Group mean relax and contract condition EMG and kinematic responses to Go trials. $\boldsymbol{E}$, SSD functions for the relax and contract conditions, showing how the probability of failing to stop on a Stop trial increased as SSD increased. $\boldsymbol{F}$, SSRT in relax and contract blocks significantly correlated $(r=0.62, p=0.024)$ across participants. $\mathbf{G}-\mathbf{I}$, Group mean relax and contract condition kinematics $(\boldsymbol{G})$, biceps EMG $(\boldsymbol{H})$, and triceps EMG $(\boldsymbol{I})$, for successful and failed Stop trials, time locked to the Stop signal. Top panels show smoothed data, while bottom panels show angle acceleration and EMG velocity traces. All error bars indicate SEM.

relaxing the biceps muscle, but during "contraction blocks" extension was achieved by contracting the triceps muscle. On a random subset (30\%) of trials, a Stop signal (tone) was presented. Stop signal onset time in relation to the Go signal varied between 0 and $500 \mathrm{~ms}$ (Stop signal delay). There were six tone intervals $(0,100,200,300,400$, and $500 \mathrm{~ms}$; randomized).

Each block consisted of 80 trials ( 40 Go trials, 24 Stop trials, 8 No-Go trials with tone, 8 No-Go trials without tone). There were 10 blocks in total ( 5 relax, 5 contract). The experiment lasted $\sim 3 \mathrm{~h}$.

Procedure for experiment 2. Procedural details were the same as those for experiment 1, with three important differences. First, the target muscle in the contract condition was the biceps, and the Go response in this condition involved flexing the elbow (see Fig. $3 A$ ). The relax condition was the same as experiment 1 . Second, relax and contract conditions were tested within the same blocks. Third, we did not include No-Go trials. Participants were instructed to relax their right biceps muscle in response to a blue circle appearing on the screen ( $50 \%$ of trials; randomized) and contract their right biceps muscle in response to a blue square ( $50 \%$ of trials; randomized). Stimulus-action pairing was counterbalanced across participants. Stop signals were the same as experiment 1 . There were 10 experimental blocks of 80 trials ( 28 relax condition Go trials, 12 relax condition Stop trials, 28 contract condition Go trials, 12 contract condition Stop trials).

Procedure for experiment 3. Experiment 3 was different from experiment 2 because the target muscle was the right FDI, the Go response involved isometric increases and decreases of force, and the Stop signal used dynamic rather than fixed SSDs. Participants rested their arm on a table in a pronated position (see Fig. $5 \mathrm{~A}$ ) with the outside of their right index finger touching a force sensor. They pushed outward (abduction) with $\sim 10 \%$ MVC to move a small black circle between two boundary 
lines on screen. These lines, and an additional target line representing a force of $20 \%$ MVC, were shown during training, but were removed during the actual task once a stable force was achieved at the start of each trial. Go signals were presented after variable ISIs (1-4 s). Participants had to rapidly decrease FDI muscle activity to 0 if a circle appeared (relax condition) and rapidly increase it by $\sim 10 \%$ if a square appeared (contract condition).

SSD on Stop trials (30\% of trials) was adjusted from an initial $250 \mathrm{~ms}$ by increasing it by $50 \mathrm{~ms}$ every time participants successfully stopped and decreasing it by $50 \mathrm{~ms}$ every time they failed to stop. Staircasing was performed separately for each condition (relax vs contract). This one-up one-down method is commonly used in Stop signal experiments and requires online trial classification (Osman et al., 1986; Logan et al., 1997; Verbruggen and Logan, 2009). We classified Stop trials by setting a force change threshold based on the mean maximum force "velocity" (first derivative of force increase/decrease) during the Go trials of the previous run. Exceeding 30\% of this value during the response window meant a Stop trial was classified as a failed Stop trial. Trials under threshold were classified as successful Stop trials. There were 10 runs of 60 trials (21 relax Go trials, 9 relax Stop trials, 21 contract Go trials, 9 contract Stop trials per run). The experiment lasted $\sim 3 \mathrm{~h}$.

Analysis. Elbow angle velocity was determined in experiments 1 and 2 by calculating the angle change (relative to baseline. -2000 to $0 \mathrm{~ms}$ ) among three reflective markers located on the upper arm, elbow, and forearm. The angular change data were smoothed (zero-phase digital filtering; low pass $10 \mathrm{~Hz}$ ), and the velocity was calculated by taking the difference between successive time points. Acceleration was calculated by taking the difference between successive time points of the velocity data. Force velocity was calculated in experiment 3 by taking the difference between successive time points of the smoothed force data (zero-phase digital filtering; low pass $5 \mathrm{~Hz}$ ).

Response time (RT) was the point after the Go signal where the angular velocity first rose above $10 \%$ of the maximum velocity on that trial (Irlbacher et al., 2006; De Havas et al., 2016). Outliers $(>4 \times$ SD) were reassigned to the value of the slowest nonoutlier trial to ensure SSRT calculations were unbiased (Verbruggen and Logan, 2009). In experiment 3 , we used a threshold of $30 \%$ because the force signal contained more noise.

EMG data in all experiments was bandpass filtered (zero-phase digital filtering; $10-500 \mathrm{~Hz}$ ) and rectified, before being smoothed (zerophase digital filtering; low pass $10 \mathrm{~Hz}$ ). EMG velocity was calculated by taking the difference between successive time points in the smoothed data. We determined EMG-RT on Go trials via the threshold technique (first time point $>30 \%$ of the maximum, which remained above threshold for at least $25 \mathrm{~ms}$ ).

Stop trial success was classified online in experiment 3 (see procedure), but in experiments 1 and 2 it was classified offline by first calculating the mean peak go trial velocity separately for each movement type for each participant. Stop trials were coded as successful if the velocity never rose above $10 \%$ of the mean maximum Go trial velocity, but as failed if the threshold was exceeded. In all experiments, the failed Stop trial RT was the point relative to the Go signal where the velocity first rose above the Stop classifier threshold. Outliers were dealt with in the same manner as for Go trials. All calculations were performed independently for the relax and contract conditions. Response times were compared across conditions using within subject $t$ tests.

In experiment 3 , we calculated the mean probability of movement (pMov) in each movement condition (total failed Stop trials divided by total Stop trials). In experiments 1 and 2, pMov was calculated at each $\mathrm{SSD}$, in each movement condition in the same manner. One-way within-subject ANOVAs were used to verify that pMov increased across the six levels of SSD in each movement condition. Inhibition functions were fit to the pMov data using the Weibull method (Hanes and Schall, 1995). We used MATLAB (version 2017a) and the Palamedes curve-fitting toolkit (Prins and Kingdom, 2018), with a four-parameter model ( $\alpha=$ scale, $\beta=$ shape, $\gamma=$ lower bias, $\lambda=$ upper bias). Lower and upper biases in this context are synonymous with error rate, and in the SST literature consist of trials where Stop (trigger failure) and Go (forced inhibition) processes are not initiated (Band et al., 2003). Both bias parameters were restricted to 0.05 (Livesey and Livesey, 2016). Beta values were compared via $t$ test to determine whether inhibition functions differed in shape across relax and contract conditions.

SSRT was calculated in experiment 3 by subtracting the mean SSD from the Go trial response time in each movement condition (Verbruggen et al., 2019). In experiments 1 and 2, SSRT was calculated using the integration method, which is commonly used for fixed SSDs (Logan and Cowan, 1984) and was necessary because we did not tightly constrain performance, leading to heterogeneity in SSD curves (Verbruggen and Logan, 2009). Go RTs were rank ordered from smallest to largest. For each SSD, the total number of Go RT trials was multiplied by the pMov at that SSD. This value was rounded to the nearest integer, and the corresponding Go RT in the rank-ordered list was selected. The SSD itself was then subtracted from this Go RT to give the SSRT at that SSD. Overall, SSRT was then calculated by taking the mean of all the SSRTs obtained, separately for the relax and contract conditions.

SSRTs were compared across movement conditions in all experiments via within-subjects $t$ tests and Pearson's $r$. To discount the possibility that experiment 1 was underpowered and to avoid type II errors, we applied a Bayesian analysis (Dienes, 2008, 2014) to experiments 2 and 3 using the mean difference between conditions obtained in experiment 1 (half-normal distribution, one tailed).

In all experiments, active breaking was defined as a consistent Stop signal-related change in the elbow angle acceleration (experiments 1 and 2 ), force velocity (experiment 3), or EMG velocity (experiments 1,2, and 3 ) that could not be ascribed to the Go signal. In experiments 1 and 2, kinematic active breaking was determined from angle acceleration to control for the large deviations in position and velocity on failed Stop trials. In all cases, we first removed any Stop trials where early movements occurred in the opposite direction to that which would be expected if it was a Go trial (mean number of trials removed per subject: experiment $1,0.6 \%$; experiment 2, 1.6\%; experiment 3, 2.18\%). Next, through visual inspection of group average kinematic, force, and EMG data, we determined the direction (positive or negative) of active breaking, separately for successful and failed Stop trials in each movement condition. Active breaking onset times were calculated separately for elbow angle acceleration, force velocity, and EMG velocity. For a given signal, onset time was defined at the individual participant level by taking the first time point $0-500 \mathrm{~ms}$ after the Stop signal that reached $30 \%$ of its maximum or minimum value (depending on active breaking direction) within the same window. To determine whether active breaking was significant at the group level, we averaged the signal in a $50 \mathrm{~ms}$ window time locked to active breaking onset for each participant and compared these values to 0 via one-sample $t$ tests [Fig. 2 (see also Figs. 4, 6)]. After confirming the presence of active breaking at the group level, the analysis was repeated across trials at the individual participant level and tested via one-sample $t$ test (one tailed).

In experiment 1 , in the relax condition the primary muscle was the biceps and the secondary muscle was the triceps. Some participants $(n=5)$ showed evidence of increased triceps activity before the Stop signal on some trials and were excluded from the secondary muscle analyses to minimize false-positive detection of active breaking. In the contract condition, the primary muscle was the triceps and the secondary muscle was the biceps. Again, we had to remove some participants $(n=5)$ who showed early pre-Stop signal activation of the secondary muscle. In experiment 2 , as before, the biceps was the primary muscle and the triceps was the secondary muscle in the relax condition $(n=5$ excluded from secondary muscle analysis, due to pre-Stop signal activity on some trials). Likewise, in the contract condition the biceps was the primary muscle and the triceps was the secondary muscle. One participant was excluded from the secondary muscle analysis because triceps EMG active breaking occurred very late relative to the Stop signal $(>300$ $\mathrm{ms}$ ), and after the kinematic active breaking onset, meaning it was a reaction to the arm stopping rather than a cause. Finally, in experiment 3 , the FDI was the primary muscle in both movement conditions.

We performed a further analysis on successful Stop trials to determine the following: (1) whether active breaking occurred when kinematics/force traces were flat; and (2) how active breaking magnitude changed with a decreasing detected Go response. In all experiments, 

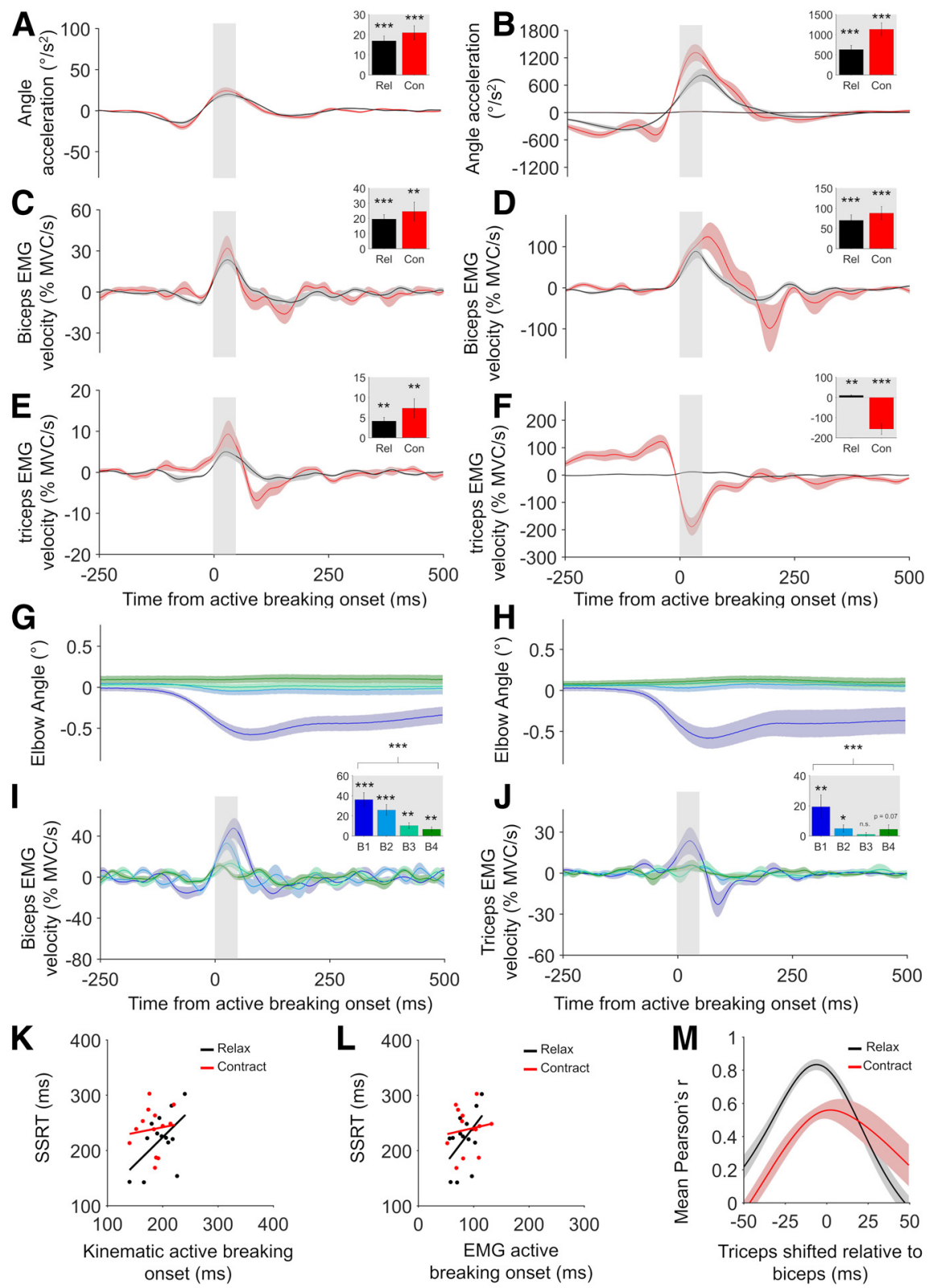

Figure 2. Active breaking results for experiment 1. $A, B$, Group mean kinematic active breaking results for successful $(\boldsymbol{A})$ and failed $(\boldsymbol{B})$ Stop trials in the relax and contract conditions. Successful Stop trials were also plotted on the failed Stop trial graph for comparison. Traces always aligned to active breaking onset times derived at the individual participant level. Inserts show mean values obtained during the $50 \mathrm{~ms}$ shaded window immediately after active breaking onset. $\boldsymbol{C}$, D, Group mean biceps EMG active breaking results for successful $(\boldsymbol{C})$ and failed $(\boldsymbol{D})$ Stop trials for the relax and contract conditions. Active breaking was significantly positive for all conditions. $\boldsymbol{E}, \boldsymbol{F}$, Group mean triceps EMG active breaking results for successful $(\boldsymbol{E})$ and failed $(\boldsymbol{F})$ Stop trials. Active breaking was significantly positive in the relax condition and significantly negative for failed Stop trials in the contract condition. But for successful Stop trials it was significantly positive (see text for details). $\mathbf{G}, \boldsymbol{H}$, Successful Stop trial kinematics in the relax $(\boldsymbol{G})$ and contract $(\boldsymbol{H})$ conditions after trials were sorted into quartiles according to the amount of the Go response. I, Positive biceps EMG active breaking was present in the relax condition even when the kinematics were flat. $J, A$ trend was observed for the triceps in the contract condition. Active breaking amplitude decreased significantly across bins in both cases, as the detected $G$ response decreased. $\boldsymbol{K}, \boldsymbol{L}$, Positive correlations between kinematic $(\boldsymbol{K})$ and EMG $(\boldsymbol{L})$ active breaking onset times and SSRT reached significance in the relax, but not the contract condition. $\boldsymbol{M}$, Time-shifted cross-correlation showed that peak correlation between biceps and triceps active breaking was close to $0 \mathrm{~ms}$ in both conditions, indicating simultaneous action. All error bars indicate SEM. Results of statistical tests are shown indicated by asterisks: ${ }^{* *} p<0.001$, ${ }^{* *} p<0.01,{ }^{*} p<0.05$. n.s. $=$ not significant.

successful Stop trials were split into quartiles at the individual participant level after rank ordering them according to the amplitude of go response detected in the smoothed kinematic or force traces before the Stop signal onset $(-1000$ to $0 \mathrm{~ms})$. Primary muscle active breaking amplitude was then calculated for trials in each of the four bins. This was done at the group level in the same manner as described above, using the already derived active breaking onset times (based on all successful Stop trials) for time locking.

Mean individual active breaking onset times were calculated by taking the average between successful and failed Stop trials, separately for kinematic force and primary muscle EMG in each movement condition. Mean active breaking times were then correlated to SSRT in all experiments via Pearson's $r$, under a one-tailed assumption that all correlations were expected to be positive.

Primary and secondary muscle active breaking onset times were compared via paired-sample $t$ tests in experiment 1 (relax, $n=8$; contract, $n=8$ ) and experiment 2 (relax, $n=7$; contract, $n=11$ ). A time-shifted cross-correlation analysis was performed to determine whether active breaking in one muscle predicted active breaking in the other after some reliable time delay. Absolute triceps muscle EMG velocity traces were shifted $(-50$ to $50 \mathrm{~ms})$ in $0.5 \mathrm{~ms}$ increments relative to the biceps muscle active breaking onset time. After each shift, cross-correlation was performed (Pearson's $r$ ) during a window that included the whole active breaking response (EMG velocity traces in both muscles, -10 to $250 \mathrm{~ms}$ relative to biceps muscle active breaking onset). The reverse calculation was also performed (i.e., biceps shifted relative to triceps), and the results were averaged together after the time axis had been reversed to ensure that results were in the same direction. This was done to control for any biases in how onset times were detected across muscles. Thus, in both cases, if correlations peaked reliably before $0 \mathrm{~ms}$, it indicated that the biceps activity predicted the triceps activity, and if correlations peaked reliably after $0 \mathrm{~ms}$, it indicated that triceps activity predicted the biceps activity. Positive peaks close to $0 \mathrm{~ms}$ indicated simultaneous action. The analysis was performed at the individual participant level. Successful and failed Stop trial results were then averaged, and group averages were calculated for relax and contract conditions in each experiment [Fig. $2 M$ (see also Fig. 4M)].

\section{Results}

\section{Go trial response times}

Go trial response times were faster in the contract condition than the relax condition in experiment 1 (521.28 vs $554.74 \mathrm{~ms} ; t_{(12)}=2.511, p=0.027$, Cohen's $\mathrm{d}=0.57$; Table 1) and experiment 2 (549.82 vs $588.36 ; t_{(11)}=3.879, p=0.003$, Cohen's d = 0.77; Table 2), but did not differ in experiment 3 (595.11 vs $598.01 \mathrm{~ms}$; $t_{(13)}=0.26, p=0.799$, Cohen's $\mathrm{d}=0.05$; Table 3). In experiment 1 , for the relax condition the biceps EMG-RT was faster than the triceps ( $311.01 \mathrm{vs} 390.61 \mathrm{~ms} ; t_{(12)}=-3.572, p=0.004$, Cohen's $d=-1.17)$. In the contract condition, the biceps muscle began to relax earlier than the triceps muscle started to contract (331.05 vs $417.18 \mathrm{~ms} ; t_{(12)}=-6.036, p<0.001$, Cohen's $\mathrm{d}=-1.56$ ). 
Table 1. Response times for experiment 1

\begin{tabular}{llllll}
\hline Condition & Go trial RT & Go trial biceps EMG-RT & Go trial triceps EMG-RT & Failed Stop trial RT & SSRT \\
\hline Relax & $554.74 \mathrm{~ms}(54.21 \mathrm{~ms})$ & $311.01 \mathrm{~ms}(32.3 \mathrm{~ms})$ & $390.61 \mathrm{~ms}(90.3 \mathrm{~ms})$ & $497.02 \mathrm{~ms}(39.44 \mathrm{~ms})$ & $220.46 \mathrm{~ms}(49.42 \mathrm{~ms})$ \\
Contract & $521.28 \mathrm{~ms}(62.02 \mathrm{~ms})$ & $331.05 \mathrm{~ms}(51.09 \mathrm{~ms})$ & $417.18 \mathrm{~ms}(59.17 \mathrm{~ms})$ & $461.27 \mathrm{~ms}(39.74 \mathrm{~ms})$ & $238.51 \mathrm{~ms}(40.09 \mathrm{~ms})$ \\
\hline
\end{tabular}

Table shows group mean (SD) behavioral response times for Go trials and response times for onset of muscle activity changes on Go trials. Both muscles were relaxing in the relax condition, but in the contract condition the triceps muscle was contracting and the biceps muscle was relaxing. Behavioral response times on Stop trials where movement occurred are also shown along with SSRT.

Table 2. Response times for experiment 2

\begin{tabular}{lllll}
\hline Condition & Go Trial RT & Go Trial biceps EMG-RT & Go Trial triceps EMG-RT & Failed Stop trial RT \\
\hline Relax & $588.36 \mathrm{~ms}(56.51 \mathrm{~ms})$ & $331.76 \mathrm{~ms}(36.9 \mathrm{~ms})$ & $416.21 \mathrm{~ms}(77.43 \mathrm{~ms})$ & $543.98 \mathrm{~ms}(41.17 \mathrm{~ms})$ \\
Contract & $549.82 \mathrm{~ms}(42.18 \mathrm{~ms})$ & $437.79 \mathrm{~ms}(33.97 \mathrm{~ms})$ & $440.08 \mathrm{~ms}(32.84 \mathrm{~ms})$ & $504.46 \mathrm{~ms}(32.47 \mathrm{~ms})$ \\
\hline
\end{tabular}

Table shows group mean (SD) behavioral response times for Go trials and response times for onset of muscle activity changes on Go trials. Both muscles were relaxing in the relax condition and contracting in the contract condition. Behavioral response times on Stop trials where movement occurred are also shown along with SSRT.

Table 3. Response times for experiment 3

\begin{tabular}{lllr}
\hline Condition & Go Trial RT & Go Trial FDI EMG-RT & Failed Stop trial RT \\
\hline Relax & $598.01 \mathrm{~ms}(54.8 \mathrm{~ms})$ & $424.29 \mathrm{~ms}(47.98 \mathrm{~ms})$ & $511.11 \mathrm{~ms}(55.52 \mathrm{~ms})$ \\
Contract & $595.11 \mathrm{~ms}(63.59 \mathrm{~ms})$ & $445.21 \mathrm{~ms}(52.95 \mathrm{~ms})$ & $489.73 \mathrm{~ms}(53.79 \mathrm{~ms})$ \\
\hline
\end{tabular}

Group mean (SD) behavioral response time for Go trials, Go trial FDI EMG response times, failed Stop trial behavioral response times, and SSRT in the relax and contract conditions.

In experiment 2, the biceps muscle EMG-RT was again faster than the triceps muscle in the relax condition (331.76 vs $416.21 \mathrm{~ms}$; $t_{(11)}=-4.083, p=0.002$, Cohen's $\left.\mathrm{d}=-1.39\right)$. Biceps and triceps muscle EMG-RT did not differ in the contract condition, when both were contracting $\left(437.79 \mathrm{vs} 440.08 \mathrm{~ms} ; t_{(11)}=-0.852, p=\right.$ 0.412, Cohen's $\mathrm{d}=-0.07)$. However, comparing directly between the relax and contract conditions in the biceps showed relaxation was indeed faster $\left(t_{(11)}=-11.003, p<0.001\right.$, Cohen's $\left.d=-2.99\right)$. Thus, relaxation was faster than contraction in the forearm, particularly in the biceps muscle. However, in the FDI muscle (experiment $3)$, there was only a trend for relaxation being faster than contraction (424.29vs $445.21 \mathrm{~ms} ; t_{(13)}=-1.982, p=0.069$, Cohen's $\mathrm{d}=$ $-0.41)$.

\section{Stopping muscle relaxations not impaired relative to stopping contractions}

In experiment 1 , contract SSRT $($ mean $=238.51 \mathrm{~ms} ; \mathrm{SD}=$ $49.42 \mathrm{~ms}$ ) and relax SSRT (mean $=220.46$; SD $=49.42)$ did not significantly differ $\left(t_{(12)}=1.628, p=0.129\right.$, Cohen's $d=0.401$, observed power $=0.266$ ). There was also no significant difference in SSRT between contract and relax conditions in experiment 2 $($ mean $=256.5 \mathrm{~ms}, \mathrm{SD}=31.69$; vs mean $=268.1 \mathrm{~ms}, \mathrm{SD}=48.31$; $t_{(11)}=-0.992, p=0.34$, Cohen's $\mathrm{d}=-0.284$, observed power $=$ 0.147 ) and experiment 3 (mean $=156.86 \mathrm{~ms}$; $\mathrm{SD}=69.84$; vs mean $=170.98 \mathrm{~ms} ; \mathrm{SD}=58.94 ; t_{(13)}=-1.31, p=0.213$, Cohen's $\mathrm{d}=-0.219$, observed power $=0.118$ ).

Bayesian analysis of experiments 2 and 3, using the mean difference between conditions in experiment 1 (half-normal distribution, one tailed), was consistent with weak support for the null hypothesis in experiment 2 (mean difference $=-11.599, \mathrm{SE}=$ 13.314; likelihood of theory $=0.0076$; likelihood of null $=0.021$; Bayes factor $=0.369)$ and support for the null in experiment 3 (mean difference $=-14.124, \mathrm{SE}=11.886$; likelihood of theory $=$ 0.0048 ; likelihood of null $=0.0166$; Bayes factor $=0.291$ ). This suggests that SSRT does not differ across muscle contractions and relaxations.

The race model can be applied to stopping muscle relaxations

Experiment 1 and 2 had a fixed SSD design. In line with the race model, the probability of failing to inhibit a response increased with increasing SSD across movement conditions (Figs. 1E, 2C). The effect was strong for the relax condition $\left(F_{(5,60)}=100.937\right.$, $\left.p<0.001, \eta \mathrm{p}^{2}=0.89\right)$ and the contraction condition $\left(F_{(5,60)}=\right.$ $\left.79.418, p<0.001, \eta \mathrm{p}^{2}=0.87\right)$ in experiment 1 , and for the relax $\left(F_{(5,55)}=112.86, p<0.001, \eta \mathrm{p}^{2}=0.91\right)$ and contract conditions $\left(F_{(5,55)}=97.403, p<0.001, \eta \mathrm{p}^{2}=0.9\right)$ in experiment 2 .

Weibull functions showed a highdegree of fit to the probability of stopping data (Figs. $1 E, 2 C$ ). In the first experiment, mean adjusted $R^{2}$ was $0.90(\mathrm{SD}=0.13)$ in the relax condition and 0.81 $(\mathrm{SD}=0.18)$ in the contract condition. In experiment $2, R^{2}$ was $0.89(\mathrm{SD}=0.15)$ in the relax condition and $0.84(\mathrm{SD}=0.24)$ in the contract condition. The shape of these SD curves was similar across movement conditions. The mean Weibull $\beta$-parameter values were $4.23(\mathrm{SD}=1.95)$ for the relax condition and 3.34 $(\mathrm{SD}=1.48)$ for the contract conditions in experiment $1\left(t_{(12)}=\right.$ 1.73, $p=0.11$, Cohen's $\mathrm{d}=0.51)$, and $4.35(\mathrm{SD}=1.43)$ for the relax condition and $3.97(\mathrm{SD}=1.6)$ for the contract condition $\left(t_{(11)}=0.88, p=0.4\right.$, Cohen's $\left.d=0.25\right)$ in experiment 2 .

Experiment 3 used a variable SSD design. Despite independent staircasing, the probability of moving (i.e., failed Stop trials/ total Stop trials) did not differ between the relax condition (mean $=0.48, \mathrm{SD}=0.04)$ and the contract condition (mean = $0.47, \mathrm{SD}=0.05 ; t_{(13)}=1.325, p=0.21$, Cohen's $\left.d=0.17\right)$. Mean SSD was also similar for muscle relaxations (mean $=427.02 \mathrm{~ms}$, $\mathrm{SD}=55.48 \mathrm{~ms}$ ) and contractions $($ mean $=438.25 \mathrm{~ms}, \mathrm{SD}=59.97$ $\mathrm{ms} ; t_{(13)}=-0.77, p=0.45$, Cohen's $\left.\mathrm{d}=-0.19\right)$.

As predicted by the race model, mean response times were significantly faster on failed Stop trials than on Go trials across all three experiments. This held for the relax condition $\left(t_{(12)}=\right.$ 5.83, $p<0.001$, Cohen's $\mathrm{d}=1.22)$ and contract condition $\left(t_{(12)}=\right.$ $6.69, p<0.001$, Cohen's $d=1.15)$ in experiment 1 , for the relax condition $\left(t_{(11)}=6.62, p<0.001\right.$, Cohen's $\left.d=0.9\right)$ and contract condition $\left(t_{(11)}=5.22, p<0.001\right.$, Cohen's $\left.d=1.21\right)$ in experiment 2 , and for the relax condition $\left(t_{(13)}=10.58, p<0.001\right.$, Cohens $\mathrm{d}=1.58)$ and contract condition $\left(t_{(13)}=8.4, p<0.001\right.$, Cohen's $\mathrm{d}=1.79$ ) in experiment 3 .

\section{Relax SSRT and contract SSRT positively correlated}

We observed a positive correlation between relax SSRT and contract SSRT in all three experiments. In experiment $1 \quad(r=0.62$, 

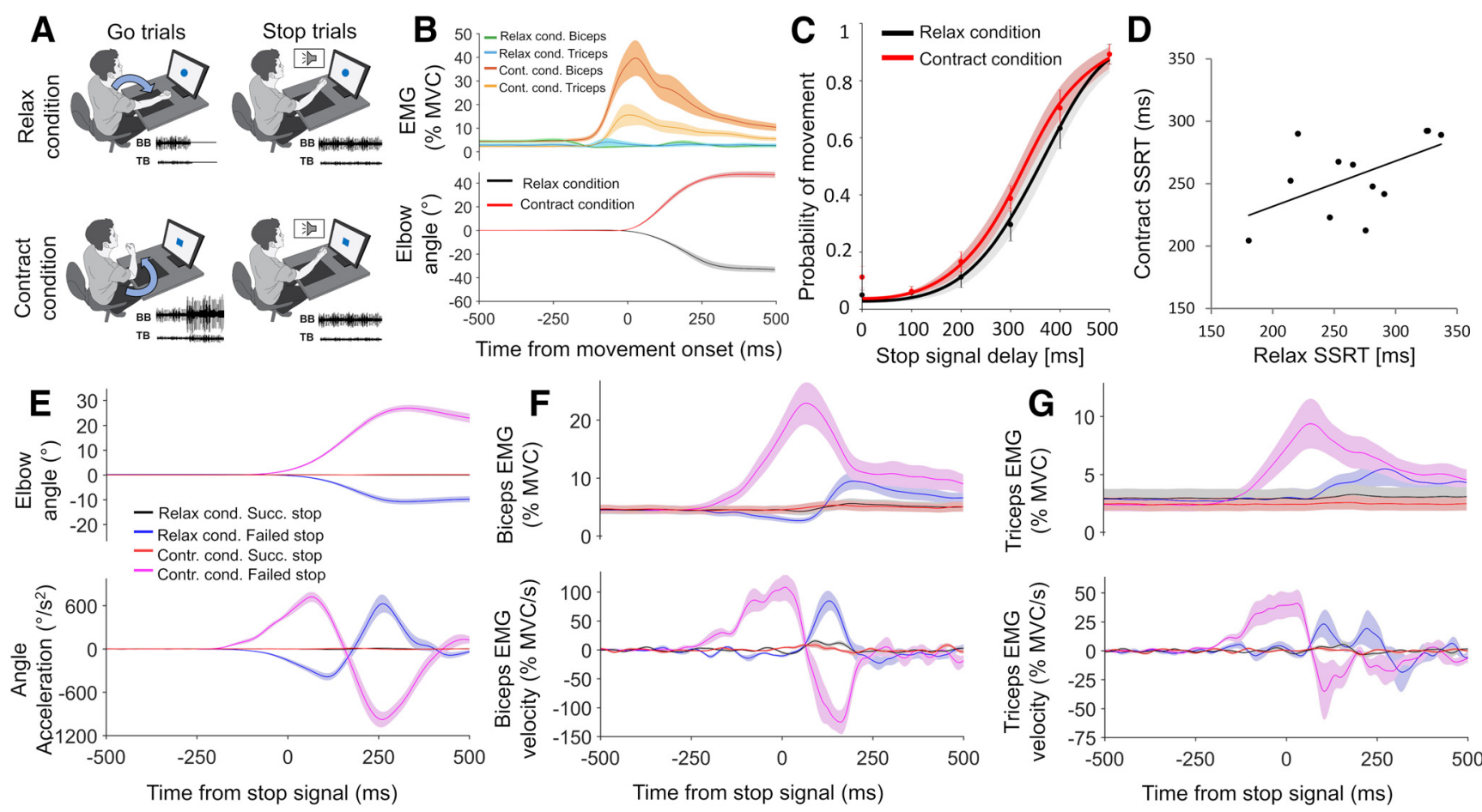

Figure 3. Design and results for experiment 2. A, On relax Go trials, participants extended the elbow by relaxing the biceps, and on contract Go trials they flexed the elbow by further contracting the biceps. They attempted to Stop these movements if a Stop signal was present. $\boldsymbol{B}$, Group mean relax and contract condition EMG and kinematic responses to Go trials. C, SSD functions for the relax and contract conditions $(\boldsymbol{C})$, showing how the probability of failing to stop on a Stop trial increased as SSD increased. $\boldsymbol{D}$, SSRT in relax and contract conditions showed a positive trend $(r=0.55, p=0.061)$ across participants $(\boldsymbol{D})$. $\boldsymbol{E}-\boldsymbol{G}$, Group mean relax and contract condition kinematics $(\boldsymbol{E})$, biceps EMG $(\boldsymbol{F})$, and triceps EMG $(\boldsymbol{G})$, for successful and failed Stop trials, time locked to the Stop signal. Top panels show smoothed data, while bottom panels show angle acceleration and EMG velocity traces. All error bars indicate SEM.

$p=0.024$; Fig. $1 F)$ and experiment $3(r=0.82, p<0.001$; see Fig. $5 C)$ the results were significant, while in experiment $2(r=0.55$, $p=0.061$; Fig. $3 D$ ) they only showed a trend toward significance.

\section{Stopping involves active breaking}

In all experiments, significant active breaking was observed at the group level for all conditions. Experiment 1 compared the stopping of elbow extensions caused either by relaxation of the biceps (relax condition) or contraction of the triceps (contract condition; Fig. 1G-I). Elbow acceleration showed positive active breaking (flexion direction) when relaxations were successfully $\left(t_{(12)}=6.903, p<0.001\right.$, Cohen's $d=1.91$; Fig. $\left.2 A\right)$ and unsuccessfully $\left(t_{(12)}=6.012, p<0.001\right.$, Cohen's $d=1.67$; Fig. $\left.2 B\right)$ stopped. Biceps EMG velocity showed positive active breaking earlier in these same successful $\left(t_{(12)}=6.862, p<0.001\right.$, Cohen's $\mathrm{d}=1.9$; Fig. $2 C)$ and failed $\left(t_{(12)}=5.125, p<0.001\right.$, Cohen's $\mathrm{d}=1.42$; Fig. $2 D$ ) Stop trials. We also tested active breaking at the individual-subject level (one tailed). All participants (13 of 13) showed significant active breaking for kinematics and EMG on successful and failed Stop trials in the relax condition.

In the contract condition, active breaking (flexion direction) was observed when examining elbow acceleration on successful $\left(t_{(12)}=6.168, p<0.001\right.$, Cohen's $d=1.71$; Fig. $\left.2 A\right)$ and failed $\left(t_{(12)}=7.188, p<0.001\right.$, Cohen's d $=1.99$; Fig. $\left.2 B\right)$ Stop trials. On failed Stop trials, when the triceps was already contracting, negative active breaking was observed $\left(t_{(12)}=-5.812, p<0.001\right.$, Cohen's $\mathrm{d}=-1.61$; Fig. $2 F$ ). Conversely, on successful Stop trials, when the biceps muscle was relaxing, but the triceps had typically not begun to contract (Table 1), positive active breaking was observed $\left(t_{(12)}=3.167, p=0.008\right.$, Cohen's $d=0.88$; Fig. $\left.2 E\right)$. Positive triceps EMG velocity increases on successful Stop trials could therefore have been contaminated with "Go response," since both involved signal increase. This was judged unlikely given the onset timing and shape of the triceps response, which was more closely related to the Stop signal across participants. After positive active breaking, a negative dip was observed (Fig. 2E, red line), which is indicative of a biphasic response, but also of later voluntary response components. As such, we analyzed only the first stop-related components of the signal in each condition. Active breaking as defined above could be detected at the individual participant level in 10 of 13 participants from the kinematics and 8 of 13 from the EMG on successful Stop trials. For failed Stop trials, it reached threshold $(p<0.1)$ in 12 of 13 participants for kinematics and 13 of 13 for triceps EMG.

In experiment 2, we compared the stopping of biceps relaxations (elbow extension) and contractions (elbow flexion; Fig. 3E$G)$. In the relax condition, the results replicated those seen in experiment 1. Positive active breaking was observed from the kinematics for successful $\left(t_{(11)}=6.04, p<0.001\right.$, Cohen's $d=1.74$; Fig. $4 A)$ and failed $\left(t_{(11)}=5.447, p<0.001\right.$, Cohen's $d=1.57$; Fig. $4 B$ ) stops and from the biceps EMG velocity for successful $\left(t_{(11)}=6.56, p<0.001\right.$, Cohen's $\mathrm{d}=1.89$; Fig. $\left.4 C\right)$ and failed $\left(t_{(11)}=4.994, p<0.001\right.$, Cohen's $d=1.44$; Fig. $\left.4 D\right)$ stops. In the contraction condition, negative active breaking was observed from the kinematics for successful $\left(t_{(11)}=-5.614, p<0.001\right.$, Cohen's d $=-1.62$; Fig. $4 A)$ and failed $\left(t_{(11)}=-8.261, p<0.001\right.$, Cohen's $\mathrm{d}=-2.38$; Fig. $4 B$ ) stops and from the biceps EMG velocity for successful $\left(t_{(11)}=-6.037, p<0.001\right.$, Cohen's $\mathrm{d}=$ -1.74 ; Fig. $4 C)$ and failed $\left(t_{(11)}=-6.51, p<0.001\right.$, Cohen's $d=$ -1.88 ; Fig. $4 D$ ) stops. At the individual-participant level, active breaking could again be detected in the majority of cases for the relax condition (kinematics: successful $=10$ of 12 ; failed $=12$ of 12; EMG: successful $=11$ of 12; failed $=12$ of 12) and for the 
contract condition (kinematics: successful $=9$ of 12 ; failed $=12$ of 12 ; EMG: successful $=10$ of 12 ; failed $=12$ of 12).

Experiment 3 had participants stopping isometric relaxations and contractions of the FDI muscle (Fig. 5D,E). Positive active breaking was found in the relax condition when examining force velocity on successful $\left(t_{(13)}=\right.$ 6.972, $p<0.001$, Cohen's $\mathrm{d}=1.86$; Fig. $6 A)$ and failed $\left(t_{(13)}=6.742, p<0.001\right.$, Cohen's $d=1.8$; Fig. $6 B$ ) Stop trials, and when examining FDI EMG velocity for successful $\left(t_{(13)}=8.139, p<\right.$ 0.001 , Cohen's $d=2.18$; Fig. $6 C$ ) and failed $\left(t_{(13)}=4.936, p<0.001\right.$, Cohen's $\mathrm{d}=1.32$; Fig. $6 D$ ) Stop trials. In the contract condition, we found negative active breaking for force velocity on successful $\left(t_{(13)}=-6.923, p<0.001\right.$, Cohen's $d=-1.85$; Fig. $6 A$ ) and failed $\left(t_{(13)}=-6.524, p<0.001\right.$, Cohen's $\mathrm{d}=$ -1.74 ; Fig. $6 B$ ) Stop trials, and for FDI EMG velocity on successful $\left(t_{(13)}=\right.$ $-7.656, p<0.001$, Cohen's $\mathrm{d}=-2.05$; Fig. $6 C)$ and failed $\left(t_{(13)}=-4.306\right.$, $p<0.001$, Cohen's $d=-1.15$; Fig. $6 D$ ) Stop trials. Active breaking was also detected in the majority of cases at the individual-participant level, both for the relax condition (force: successful = 13 of 14; failed $=13$ of 14; EMG: successful $=13$ of 14 ; failed $=14$ of 14 ) and the contract condition (force: successful $=13$ of 14 ; failed $=14$ of 14 ; EMG: successful $=14$ of 14 ; failed $=14$ of 14).

\section{Active breaking is muscle state specific}

In experiment 1 and 2 we observed active breaking of secondary muscles. In both cases for the relax condition the triceps was considered the secondary muscle, showing significant positive active breaking for successful Stop trials $\left(t_{(7)}=4.587, p=0.003\right.$, Cohen's d $=1.62$; Fig. $2 E$ ) and failed Stop trials $\left(t_{(7)}=4.96, p=0.002\right.$, Cohen's $\mathrm{d}=1.75$; Fig. $2 F$ ) in experiment 1 , and significant positive active breaking for successful Stop trials $\left(t_{(6)}=3.901, p=\right.$ 0.008 , Cohen's $d=1.47$; Fig. $4 E$ ) and failed Stop trials $\left(t_{(6)}=2.547, p=0.045\right.$, Cohen's $d=0.96$; Fig. $4 F$ ) in experiment 2 . In experiment 1 , the biceps muscle was the secondary muscle in the contract condition, and significant positive active breaking was found on successful $\left(t_{(7)}=4.01, p=0.005\right.$, Cohen's $d=1.42$; Fig. $\left.2 C\right)$ and failed $\left(t_{(7)}=5.125, p<0.001\right.$, Cohen's $d=1.91$; Fig. $\left.2 D\right)$ Stop trials. Here the active breaking was positive because the biceps muscle was relaxing in response to the Go signal. Conversely, in the
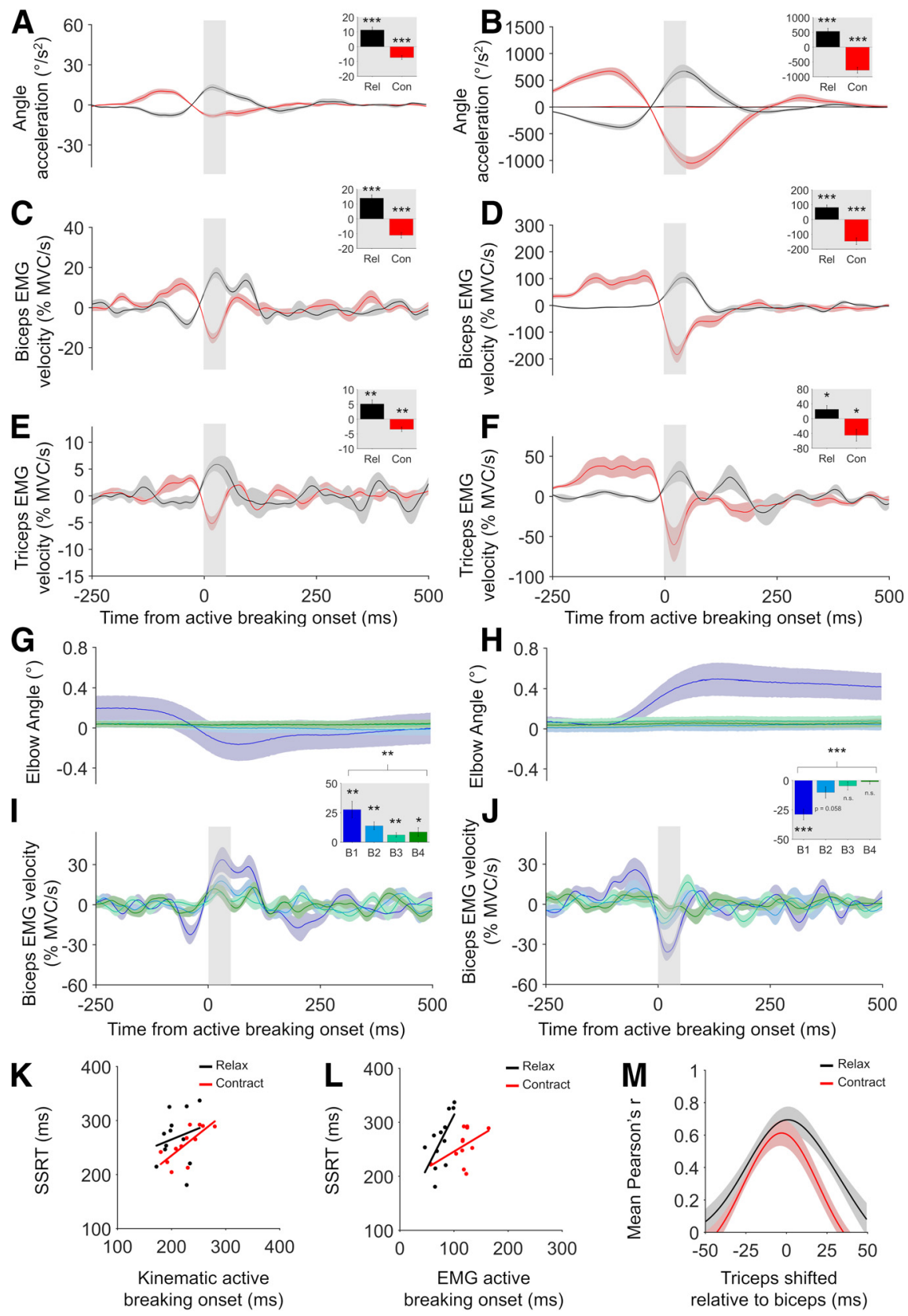

Figure 4. Active breaking results for experiment 2. $\boldsymbol{A}, \boldsymbol{B}$, Group mean kinematic active breaking results for successful $(\boldsymbol{A})$ and failed $(B)$ Stop trials in the relax and contract conditions. Successful Stop trials also plotted on the failed Stop trial graph for comparison. Inserts show mean values obtained during the $50 \mathrm{~ms}$ window immediately after active breaking onset. $\boldsymbol{C}-\boldsymbol{F}$, Group mean biceps EMG active breaking results for successful $(\boldsymbol{C})$ and failed $(\boldsymbol{D})$ Stop trials, and mean triceps EMG active breaking results for successful $(\boldsymbol{E})$ and failed $(\boldsymbol{F})$ Stop trials. Active breaking was always significantly positive in the relax condition and significantly negative in the contract condition. $\boldsymbol{G}, \boldsymbol{H}$, Successful Stop trial kinematics in the relax $(\boldsymbol{G})$ and contract $(\boldsymbol{H})$ conditions after sorting by the amount of detected Go response. $I$, Positive biceps EMG active breaking was present in the relax condition even when the kinematics were flat. $\boldsymbol{J}$, In the contract condition negative active breaking was not significant in B4. Active breaking amplitude decreased significantly across bins in the relax and contract conditions. $\boldsymbol{K}, \boldsymbol{L}$, Positive correlations between kinematic $(\boldsymbol{K})$ and EMG $(\boldsymbol{L})$ active breaking onset times and SSRT reached significance in the relax condition EMG, but only showed a trend in other cases. $\boldsymbol{M}$, Time-shifted cross-correlation showed that the peak correlation between biceps and triceps active breaking was close to $0 \mathrm{~ms}$ in both conditions, indicating simultaneous action. All error bars show SEM. Results of statistical tests shown are indicated by asterisks: ${ }^{* *} p<0.001,{ }^{* *} p<0.01,{ }^{*} p<0.05$. n.s. $=$ not significant.

contract condition in experiment 2 , the triceps (secondary muscle) tended to contract in response to the Go signal, presumably to stabilize the elbow during rapid flexion. As such, active breaking was significantly negative at the group level on successful $\left(t_{(10)}=-4.482, p=0.001\right.$, Cohen's $d=-1.35$; Fig. $\left.4 E\right)$ and failed 

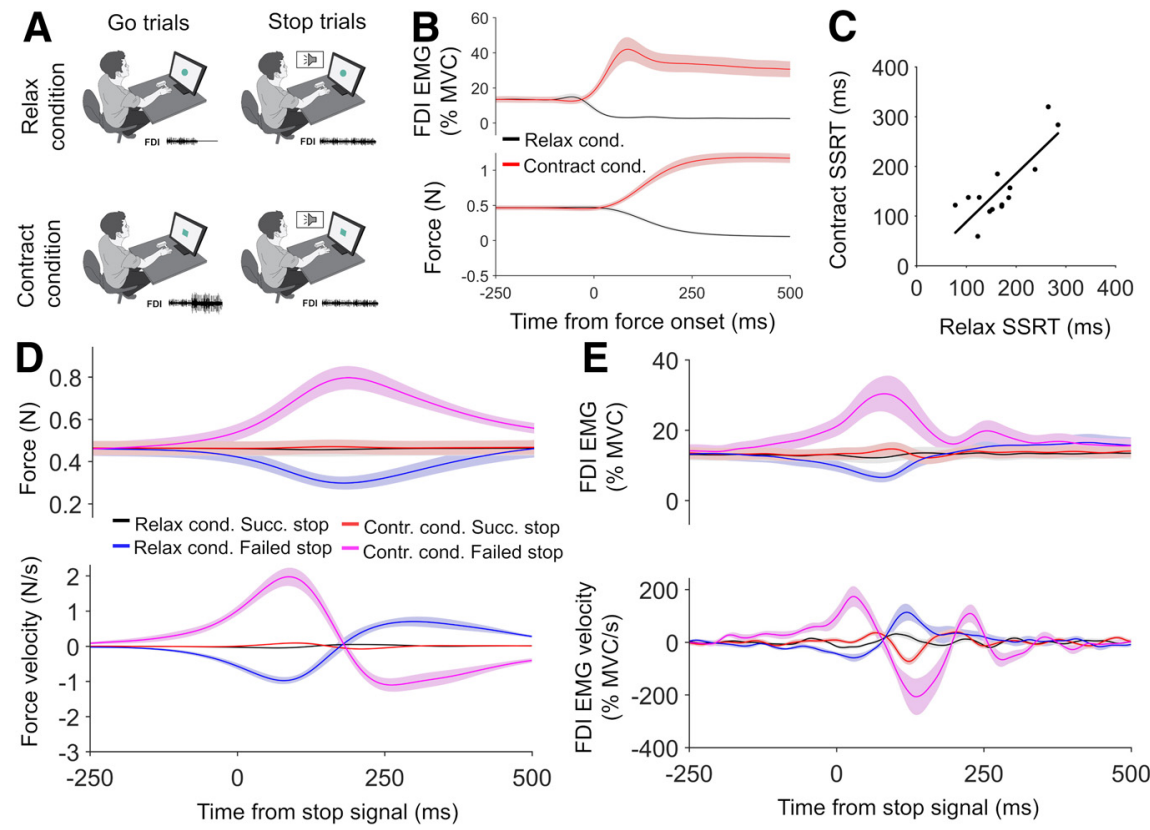

Figure 5. Design and results for experiment 3. $A, 0$ n relax Go trials, participants reduced force by relaxing the FDI, and on contract Go trials they increased force by further contracting the FDI. They attempted to stop these force changes if a Stop signal was present. $B$, Group mean relax and contract condition EMG and force responses to Go trials. $C$, SSRT in relax and contract conditions showed a significant positive correlation $(r=0.82, p<0.001)$ across participants. $\boldsymbol{D}, \boldsymbol{E}$, Group mean relax and contract condition forces $(\boldsymbol{D})$ and FDI EMG $(\boldsymbol{E})$ for successful and failed Stop trials, time locked to the Stop signal. Top panels show smoothed data, while bottom panels show velocity traces. Error bars indicate the SEM.

$\left(t_{(10)}=-2.826, p=0.018\right.$, Cohen's $\mathrm{d}=-0.85$; Fig. $\left.4 F\right)$ Stop trials.

In experiment 1 , eight of eight participants showed significant (one tailed) triceps active breaking in the relax condition on successful Stop trials and seven of eight showed significant active breaking on failed Stop trials, at the individual-participant level (one tailed). For the contract condition, seven of eight participants showed significant biceps active breaking on successful Stop trials and eight of eight participants showed significant active breaking on failed Stop trials. In experiment 2, five of seven participants showed significant triceps active breaking in the relax condition on successful Stop trials and six of seven participants showed significant active breaking on failed Stop trials. For the contract condition, 8 of 11 participants showed significant triceps active breaking on successful Stop trials and 11 of 11 showed significant active breaking on failed Stop trials.

Thus, with one exception (experiment 1 contract triceps condition, successful Stop trials; see Discussion), in all experiment and conditions we found that muscles that relaxed in response to the Go signal showed positive active breaking after the Stop signal, while muscles that contracted in response to the Go signal showed negative active breaking.

\section{Active breaking onset time correlated with SSRT}

If active breaking is causally involved in stopping, its onset time should be positively correlated with SSRT across participants. In experiment 1 (Fig. $2 K, L$ ), for the relax condition there was a moderate positive relationship between kinematic active breaking onset time and SSRT $(r=0.54, p=0.054)$ and between biceps EMG active breaking onset time and SSRT $(r=0.5, p=0.085)$, both of which reached significance (one tailed). We did not observe significant correlations in the contract condition, either for kinematic active breaking and SSRT $(r=0.11$, $p=0.714)$ or triceps EMG active breaking and SSRT $(r=0.13, p=0.6712)$.

In experiment 2 (Fig. $4 K, L$ ), while relax condition kinematic active breaking did not correlate with SSRT $(r=0.2, p=0.523)$, biceps EMG active breaking onset time did correlate significantly with SSRT $(r=0.66, p=$ $0.02)$. Moreover, in the contract condition there was a significant correlation between kinematic active breaking onset time and SSRT $(r=0.73, p=$ 0.007 ), and a trend toward a significant correlation between biceps EMG active breaking and SSRT $(r=0.46, p=0.131)$.

Finally, in experiment 3 (Fig. 6I,J) all measures of active breaking onset time significantly correlated with SSRT. This held for force $(r=0.67, p=0.0088)$ and EMG ( $r=0.67, p=0.0082)$ in the relax condition and for force $(r=83$, $p<0.001)$ and EMG $(r=0.7, p=0.005)$ in the contract condition. Thus, overall we found support for a relationship between active breaking onset time and SSRT for muscle relaxations, but weaker support for this relationship when stopping muscle contractions.

Active breaking in the absence of detectable Go response Splitting the successful Stop trials into quartiles based on the amount of putative Go response present revealed that even when the arm kinematics or finger force level were flat, active breaking was still detected after the Stop signal. This was particularly true in the relax condition, where EMG velocity in the fourth quartile (least Go response) was significantly positive in experiment 1 $\left(t_{(12)}=3.347, p=0.0058\right.$, Cohen's $d=0.93$; Fig. $\left.2 G, I\right)$, experiment $2\left(t_{(11)}=2.370, p=0.037\right.$, Cohen's $d=0.68$; Fig. $\left.4 G, I\right)$, and experiment $3\left(t_{(13)}=3.564, p=0.0035\right.$, Cohen's $d=0.95$; Fig. $\left.6 E, G\right)$. For muscle contractions, EMG velocity in the fourth quartile was significantly negative in experiment $3\left(t_{(13)}=-3.23, p=0.0066\right.$, Cohen's $d=0.86$; Fig. $6 F, H$ ), was not significant in experiment 2 $\left(t_{(11)}=-0.5, p=0.626\right.$, Cohen's $d=0.14$; Fig. $\left.4 H, J\right)$, and showed a trend toward being significant in experiment $1\left(t_{(12)}=1.958\right.$, $p=0.074$, Cohen's d = 0.54; Fig. $2 H, J)$.

\section{Active breaking amplitude decreased as Go response decreased}

The quartile analysis showed that amount of active breaking decreased as the amount of detected Go response decreased. This was true for the relax $\left(F_{(3,48)}=10.361, p<0.001, \eta \mathrm{p}^{2}=0.61\right.$; Fig. $2 I)$ and contract $\left(F_{(3,48)}=8.142, p<0.001, \eta \mathrm{p}^{2}=0.4\right.$; Fig. $\left.2 J\right)$ conditions in experiment 1 , the $\operatorname{relax}\left(F_{(3,44)}=4.734, p=0.007\right.$, $\eta \mathrm{p}^{2}=0.3$; Fig. $\left.4 I\right)$ and contract $\left(F_{(3,44)}=9.9, p<0.001, \eta \mathrm{p}^{2}=\right.$ 0.47 ; Fig. $4 J)$ conditions in experiment 2 , and the contract condition $\left(F_{(3,52)}=10.393, p<0.001, \eta p^{2}=0.44\right.$; Fig. $\left.6 H\right)$ in experiment 3 . The relax condition in experiment 3 had active breaking, which did not systematically differ across quartiles $\left(F_{(3,52)}=\right.$ $1.328, p=0.279, \eta p^{2}=0.09$; Fig. $\left.6 G\right)$. Overall, the results indicate 
that active breaking amplitude was proportional to the degree of Go response at the muscle.

\section{Comparing active breaking in relax and contract conditions}

EMG active breaking onset times were $\sim 80$ to $100 \mathrm{~ms}$ across experiments [Table 4 (see also Tables 5, 6)]. Notable exceptions were successful Stop trials in the contract condition in experiment 2, where negative active breaking onset times were $\sim 140 \mathrm{~ms}$ for both muscles (see Table 5). Direct comparison shows that active breaking onset times for the biceps muscle were significantly slower on successful than on failed Stop trials (144.29 vs $91.42 \mathrm{~ms}$; $t_{(11)}=3.62, p=0.004$, Cohen's $\left.d=1.51\right)$. However, the comparison is not strictly appropriate, since we did not observe active breaking on all successful Stop trials when the data were split into quartiles (Fig. 4J). As such, we did not compare active breaking across movement conditions in experiment 1 and 2 . The comparison was justified in experiment 3 , where active breaking was significant in all cases, but no significant difference was observed when mean onset times were compared between relax and contract conditions (94.41 vs $97.88 \mathrm{~ms} ; \quad t_{(13)}=-0.732, p=0.477$, Cohen's d $=-0.18$ ).

\section{Active breaking involves}

\section{simultaneous action across muscles}

In experiment 1 , active breaking was detected on average $18 \mathrm{~ms}$ earlier in the biceps than the triceps muscle $\left(t_{(7)}\right.$ $=-3.88, p=0.006)$ in the relax condition. However, when the entire active breaking waveform was compared in both muscles via time-shifted crosscorrelation, strong positive correlation was observed peaking at $-6 \mathrm{~ms}$ (mean peak $r=0.83, \mathrm{SD}=0.09$; Fig. $2 M$ ). This suggests that the biceps may have contracted just before the triceps, but that both muscles were likely driven by a single input, rather than the biceps activity causing the triceps activity. This was confirmed in the other conditions. In the contract condition in experiment 1, the mean onset of the triceps and biceps active breaking did not significantly differ $\left(t_{(7)}=0.764, p=0.47\right)$. Cross-correlation was weaker than in the relax condition (mean peak $r=0.56$, $\mathrm{SD}=0.17)$, but the peak correlation was again close to $0(2.5 \mathrm{~ms}$; Fig. 2M), indicating simultaneous action. Moreover, in experiment 2 biceps and triceps active breaking onset times did not differ from one another in the relax $\left(t_{(6)}=-1.124, p=0.304\right)$ or contract $\left(t_{(10)}=-0.149, p=0.884\right)$ conditions and cross-correlation suggested simultaneous action in both cases (relax peak $=1$ $\mathrm{ms}, r=0.69, \mathrm{SD}=0.22$; contract peak $=-3 \mathrm{~ms}, r=0.61, \mathrm{SD}=$ 0.26; Fig. $4 M$ ). Thus, regardless of whether active breaking was positive or negative, our results suggest that it occurred simultaneously across the observed muscles in each condition.

\section{Discussion}

Muscle relaxations were inhibited as rapidly as muscle contractions across all experiments. Our behavioral results were consistent with the race model, which argues that Stop and Go processes separately race to completion (Logan and Cowan, 1984). On this account, successful stopping will become less frequent as the delay between Go and Stop signals increases (Logan, 1994) because increasing the delay gives the Go process more time to finish. This was confirmed in experiments 1 and 2. The resulting SSD functions were similar to those obtained in previous studies (Logan et al., 1984; Schall et al., 
Table 4. Active breaking onset times experiment 1

\begin{tabular}{lllll}
\hline Movement condition & type of active breaking & Successful Stop trial onset & Failed Stop trial onset & Mean Stop trial onset \\
\hline Relax & Positive arm acceleration & $193.23 \mathrm{~ms}(32.92 \mathrm{~ms})$ & $200 \mathrm{~ms}(26.98 \mathrm{~ms})$ & $196.62 \mathrm{~ms}(27.27 \mathrm{~ms})$ \\
& Positive biceps EMG velocity & $83.12 \mathrm{~ms}(22.04 \mathrm{~ms})$ & $82.42 \mathrm{~ms}(19.74 \mathrm{~ms})$ & $82.77 \mathrm{~ms}(18.64 \mathrm{~ms})$ \\
& Positive triceps EMG velocity $(n=8)$ & $86.31 \mathrm{~ms}(14.84 \mathrm{~ms})$ & $94.69 \mathrm{~ms}(28.31 \mathrm{~ms})$ & $90.5 \mathrm{~ms}(17.14 \mathrm{~ms})$ \\
Contract & Positive arm acceleration & $199.38 \mathrm{~ms}(27.37 \mathrm{~ms})$ & $166.15 \mathrm{~ms}(37.08 \mathrm{~ms})$ & $182.77 \mathrm{~ms}(22.44 \mathrm{~ms})$ \\
& Mixed triceps EMG velocity & $92.62 \mathrm{~ms}(30.97 \mathrm{~ms})$ & $85.85 \mathrm{~ms}(25.98 \mathrm{~ms})$ & $89.23 \mathrm{~ms}(22.5 \mathrm{~ms})$ \\
& Positive biceps EMG velocity $(n=8)$ & $92.94 \mathrm{~ms}(32.23 \mathrm{~ms})$ & $95.81 \mathrm{~ms}(24.31 \mathrm{~ms})$ & $94.38 \mathrm{~ms}(26.08 \mathrm{~ms})$ \\
\hline
\end{tabular}

Mean (SD) onset time of active breaking are shown for arm acceleration and primary and secondary muscles. Active breaking onset was calculated separately for each measure, in each movement condition, for successful and failed Stop trials. This was done at the individual participant level. Mean Stop trial onset refers to the average of successful and failed Stop trial onset times. Secondary muscle data (triceps in relax condition, biceps in contract condition) could only be analyzed in a subset of participants. Note that triceps active breaking in the contract condition is labeled mixed because it was positive on successful and negative on failed Stop trials (see text for details).

Table 5. Active breaking onset times experiment 2

\begin{tabular}{|c|c|c|c|c|}
\hline Movement condition & Type of active breaking & Successful Stop trial onset & Failed Stop trial onset & Mean Stop trial onset \\
\hline \multirow[t]{3}{*}{ Relax } & Positive arm acceleration & $204.33 \mathrm{~ms}$ (29.42 ms) & 211.33 ms (29.39 ms) & $207.83 \mathrm{~ms}$ (24.16 ms) \\
\hline & Positive biceps EMG velocity & $67.25 \mathrm{~ms}$ (12.59 ms) & $86.96 \mathrm{~ms}$ (26.46 ms) & $77.1 \mathrm{~ms}$ (16.13 ms) \\
\hline & Positive triceps EMG velocity $(n=7)$ & $91 \mathrm{~ms}$ (34.87 ms) & 87.79 ms (27.47 ms) & $89.39 \mathrm{~ms}$ (25.7 ms) \\
\hline \multirow[t]{3}{*}{ Contract } & Negative arm acceleration & $260.67 \mathrm{~ms}$ (37.56 ms) & $193.33 \mathrm{~ms}$ (28.51 ms) & 227 ms (29.15 ms) \\
\hline & Negative biceps EMG velocity & $144.29 \mathrm{~ms}$ (38.84 ms) & 91.42 ms (30.71 ms) & $117.85 \mathrm{~ms}$ (24.18 ms) \\
\hline & Negative triceps EMG velocity $(n=11)$ & 140.73 ms (42.77 ms) & $96.64 \mathrm{~ms}$ (26.63 ms) & $118.68 \mathrm{~ms}$ (18.14 ms) \\
\hline
\end{tabular}

Mean (SD) onset times of active breaking are shown for arm acceleration and primary and secondary muscles. Active breaking onset was calculated separately for each measure, in each movement condition, for successful and failed Stop trials. This was done at the individual-participant level. Mean Stop trial onset refers to the average of successful and failed Stop trial onset times. Secondary muscle data (triceps) could only be analyzed in a subset of participants in the relax condition, and one participant was removed from the triceps analysis in the contract condition (see text for details).

Table 6. Active breaking onset times experiment 3

\begin{tabular}{|c|c|c|c|c|}
\hline Movement condition & Type of active breaking & Successful Stop trial onset & Failed Stop trial onset & Mean Stop trial onset \\
\hline \multirow[t]{2}{*}{ Relax } & Positive force velocity & 177.04 ms (75.94 ms) & $212.79 \mathrm{~ms}$ (62.58 ms) & $194.91 \mathrm{~ms}$ (66.01 ms) \\
\hline & Positive FDI EMG velocity & $88.21 \mathrm{~ms}$ (23.85 ms) & $100.61 \mathrm{~ms}$ (23.34 ms) & $94.41 \mathrm{~ms}$ (20.05 ms) \\
\hline \multirow[t]{2}{*}{ Contract } & Negative force velocity & 184.07 ms (78.34 ms) & $199.54 \mathrm{~ms}$ (29.61 ms) & $191.8 \mathrm{~ms}$ (51.49 ms) \\
\hline & Negative FDI EMG velocity & 99.04 ms (14.92 ms) & $96.71 \mathrm{~ms}$ (28.54 ms) & $97.88 \mathrm{~ms}$ (19.42 ms) \\
\hline
\end{tabular}

Mean (SD) onset times of active breaking are shown for force velocity and FDI EMG velocity. Active breaking onset was calculated separately for each measure, in each movement condition, for successful and failed Stop trials. This was done at the individual-participant level. Mean Stop trial onset refers to the average of successful and failed Stop trial onset times.

2017). In all conditions tested, mean response times for unsuccessful Stop trials were significantly faster than those for go trials. If there had been prolonged interaction between Stop and Go processes, then we would have observed the opposite result as the presence of the Stop signal would slow the Go response. But our results were consistent with Stop/Go independence. Failed Stop trials were faster because for a given probability of stopping (e.g., 0.5), the unsuccessful Stop trials must be drawn predominantly from the left side (faster $50 \%$ of responses) of the RT distribution, while the Go trial RT reflects the mean of the entire distribution.

We found SSRTs on the order of 150-300 ms for muscle relaxation and muscle contraction conditions, consistent with previous literature (Verbruggen and Logan, 2008; Atsma et al., 2018). Existing work had suggested shared GABAergic control in M1 might underpin the initiation of muscle relaxation and the stopping of actions (Buccolieri et al., 2004; Coxon et al., 2006; Motawar et al., 2012; Kato et al., 2019). However, we found that relax SSRTs did not differ from contract SSRTs. This lack of interference-related slowing in the relax condition argues against shared GABAergic control. Other pathways are known to be involved in action inhibition. Of particular importance is the frontostriatal hyperdirect pathway, which is involved in the reactive breaking of action (Aron et al., 2003; Aron and Poldrack, 2006). A basal ganglia account of stopping maps well onto the race model and can explain the inhibition of diverse movement such as saccades, vocalizations, reaching, grip force, and classic finger movements (de Jong et al., 1990; Hanes and Carpenter, 1999; Logan and Irwin, 2000; Mirabella et al., 2006; Xue et al., 2008; Bissett and Logan, 2012). Our finding that relax SSRT and contract SSRT significantly correlated across participants, argues for a shared control mechanism in the stopping of relaxations and contractions, possibly involving this basal ganglia circuitry.

Action inhibition is known to involve muscle excitation as well as suppression. During the cancellation of reaching, increases in motor unit firing have been recorded from the pectoralis muscle (Atsma et al., 2018). Such responses are termed active breaking because they involve additional input to the muscle that opposes the Go response (Kudo and Ohtsuki, 1998; Goonetilleke et al., 2010, 2012). As predicted, we found evidence that this mechanism operates during the stopping of muscle relaxations. Positive active breaking was consistently found across all three experiments both at the group and individual participant level for failed and successful Stop trials. These transient increases in surface EMG could be detected even on the subset of successful Stop trials where there was no detectable Go signal (i.e., kinematics/force was flat). Moreover, in all experiments we found a significant positive correlation between the onset time of EMG active breaking and SSRT in the relax condition. Active breaking may play a causative role in the stopping of muscle relaxations, akin to the theorized peripheral stopping system, which counters unwanted activity that escapes the motor cortex (de Jong et al., 1990; De Jong et al., 1995). 
We also found transient decreases in EMG when muscle contractions were cancelled. EMG decreases are expected when the excitatory drive to the muscle is interrupted, and the resulting partial responses have been reported during the Stop signal task (de Jong et al., 1990; McGarry and Franks, 1997; McGarry et al., 2000). However, our analysis showed that EMG did not simply cease to increase on these Stop trials, rather, the velocity of EMG changed direction and quickly became significantly negative, suggesting a suppressive input to the muscle (Coxon et al., 2006). Again the effect was detectable at the group and individual subject level across tasks. We therefore propose that this form of response be termed negative active breaking. The relationship between negative active breaking onset time and SSRT was less consistent than that seen for positive active breaking, with correlations being significant in experiment 3, but only showing a trend in experiment 2. Negative active breaking onset times did not differ from positive active breaking times in experiment 3, where a direct comparison was justified due to active breaking being present under all conditions, consistent with the similar SSRTs observed across conditions. However, negative active breaking was noticeably slower in experiment 2 for successful Stop trials, perhaps because proximal muscles, unlike distal muscles, only show negative active breaking when the muscle is actively shortening, due to control differences (Serrien and Baeyens, 2017). However, we cannot rule out other explanations such as increased onset variability at the trial level.

Active breaking was muscle state specific. If the Go command caused the muscle to relax, then active breaking was positive, while if the Go command caused contraction, then active breaking was negative. However, in the contract condition in experiment 1 we found negative active breaking on failed Stop trials and positive active breaking on successful Stop trials. This was likely because the biceps muscle began to relax significantly earlier in relation to the Go signal than the triceps started to contract, an EMG-RT difference that has previously been observed (Buccolieri et al., 2003). Consequently, Stop commands on successful trials tended to be executed before the triceps began to contract, but as the relax command was starting to be initiated. The critical factor determining the active breaking direction therefore may be whether a relaxation command is present centrally rather than at the muscle itself. Under such conditions the observed active breaking response may be a mix of positive and negative forms, perhaps explaining the lack of a significant correlation with SSRT in experiment 1.

Active breaking was previously observed in antagonist muscles (Atsma et al., 2018). It was therefore unclear whether the excitatory signal originates centrally or from the agonist muscle. We found active breaking in the triceps and biceps muscles in all conditions, with independently derived onset times that were similar regardless of the type of go command. When we took the entire active breaking EMG waveform for each muscle and performed time-shifted cross-correlation, we found that in all conditions there was a positive correlation and the peak was close to $0 \mathrm{~ms}$. So, activity in one muscle did not predict the activity of the other at some time delay. Rather, both muscles were likely driven by central signals and acted simultaneously.

Simultaneous positive active breaking functionally resembles cocontraction, in that it prevents unwanted movement by increasing joint stiffness (Osu and Gomi, 1999). However, when active breaking was concurrently negative in one muscle and positive in the other, the analogy with cocontraction is less clear. Positive and negative active breaking may involve a common corticostriatal pathway, but diverge afterward. Negative active breaking likely results from activity in the striatal hyperdirect pathway suddenly cutting excitatory drive to M1 (Aron et al., 2007) coupled with downstream inhibitory activity in M1 (Coxon et al., 2006; Badry et al., 2009). Reactive inhibition of this sort has a strong and generalized suppressive effect on action (Aron, 2011), which accounts for why we observed reductions of baseline FDI EMG in the absence of a Go command and why negative active breaking amplitude scaled with the current level of excitatory drive to the muscle. Importantly, we show that this cutting of excitatory drive does not extend to the positive active breaking signal, since both mechanisms can be observed on the same trials. Positive active breaking may therefore involve a separate descending pathway, perhaps driven by connections from the striatum to subcortical postural control regions (Mena-Segovia and Bolam, 2017; Takakusaki, 2017) or gain increases in the $\gamma$-motoneuron system (Johansson et al., 1986).

The cancelling of voluntary muscle relaxations was rapid, conformed to the predictions of the race model, and correlated with the time taken to cancel muscle contractions, suggesting shared high-level control. But, in the periphery we found evidence for a later divergence of control. Stopping relaxing muscles involved transient increases in muscle activity, while stopping contractions involved transient decreases in muscle activity. This active breaking correlated with SSRT and occurred simultaneously in the biceps and triceps, indicating a central origin. Negative active breaking, though known to have a general suppressive effect on activity, did not prevent positive active breaking in other, already relaxing muscles, suggesting the two forms of active breaking rely on separate pathways. The automatic coordination of positive and negative active breaking across muscle groups may explain how animals can rapidly inhibit complex actions at different stages of their execution.

\section{References}

Alegre M, Labarga A, Gurtubay IG, Iriarte J, Malanda A, Artieda J (2003) Movement-related changes in cortical oscillatory activity in ballistic, sustained and negative movements. Exp Brain Res 148:17-25.

Aron AR (2011) From reactive to proactive and selective control: developing a richer model for stopping inappropriate responses. Biol Psychiatry 69: e55-e68.

Aron AR, Poldrack RA (2006) Cortical and subcortical contributions to stop signal response inhibition: role of the subthalamic nucleus. J Neurosci 26:2424-2433.

Aron AR, Fletcher PC, Bullmore ET, Sahakian BJ, Robbins TW (2003) Stopsignal inhibition disrupted by damage to right inferior frontal gyrus in humans. Nat Neurosci 6:115-116.

Aron AR, Durston S, Eagle DM, Logan GD, Stinear CM, Stuphorn V (2007) Converging evidence for a fronto-basal-ganglia network for inhibitory control of action and cognition. J Neurosci 27:11860-11864.

Atsma J, Maij F, Gu C, Medendorp WP, Corneil BD (2018) Active braking of whole-arm reaching movements provides single-trial neuromuscular measures of movement cancellation. J Neurosci 38:4367-4382.

Badry R, Mima T, Aso T, Nakatsuka M, Abe M, Fathi D, Foly N, Nagiub H, Nagamine T, Fukuyama H (2009) Suppression of human cortico-motoneuronal excitability during the Stop-signal task. Clin Neurophysiol 120:1717-1723.

Band GP, van Boxtel GJ (1999) Inhibitory motor control in stop paradigms: review and reinterpretation of neural mechanisms. Acta Psychol (Amst) 101:179-211. 
Band GPH, van der Molen MW, Logan GD (2003) Horse-race model simulations of the stop-signal procedure. Acta Psychol (Amst) 112: $105-142$.

Bissett PG, Logan GD (2012) Post-stop-signal slowing: strategies dominate reflexes and implicit learning. J Exp Psychol Hum Percept Perform 38:746-757.

Brainard DH (1997) The Psychophysics toolbox. Spat Vis 10:433-436.

Buccolieri A, Avanzino L, Trompetto C, Abbruzzese G (2003) Relaxation in distal and proximal arm muscles: a reaction time study. Clin Neurophysiol 114:313-318.

Buccolieri A, Abbruzzese G, Rothwell JC (2004) Relaxation from a voluntary contraction is preceded by increased excitability of motor cortical inhibitory circuits: mechanisms of voluntary relaxation. J Physiol 558: 685-695.

Chae J, Yang G, Park BK, Labatia I (2002) Delay in initiation and termination of muscle contraction, motor impairment, and physical disability in upper limb hemiparesis. Muscle Nerve 25:568-575.

Chae J, Quinn A, El-Hayek K, Santing J, Berezovski R, Harley M (2006) Delay in initiation and termination of tibialis anterior contraction in lower-limb hemiparesis: relationship to lower-limb motor impairment and mobility. Arch Phys Med Rehabil 87:1230-1234.

Coxon JP, Stinear CM, Byblow WD (2006) Intracortical inhibition during volitional inhibition of prepared action. J Neurophysiol 95:33713383.

De Havas J, Ghosh A, Gomi H, Haggard P (2016) Voluntary motor commands reveal awareness and control of involuntary movement. Cognition 155:155-167.

de Jong R, Coles MGH, Logan GD, Gratton G (1990) In search of the point of no return: the control of response processes. J Exp Psychol Hum Percept Perform 16:164-182.

De Jong R, Coles MG, Logan GD (1995) Strategies and mechanisms in nonselective and selective inhibitory motor control. J Exp Psychol Hum Percept Perform 21:498-511.

Dienes Z (2008) Understanding psychology as a science: an introduction to scientific and statistical inference. New York: Palgrave Macmillan.

Dienes Z (2014) Using Bayes to get the most out of non-significant results. Front Psychol 5:781.

Dimitrov B (1985) Brain potentials related to the beginning and to the termination of voluntary flexion and extension in man. Int J Psychophysiol 3:13-22.

Goonetilleke SC, Doherty TJ, Corneil BD (2010) A within-trial measure of the stop signal reaction time in a head-unrestrained oculomotor countermanding task. J Neurophysiol 104:3677-3690.

Goonetilleke SC, Wong JP, Corneil BD (2012) Validation of a within-trial measure of the oculomotor stop process. J Neurophysiol 108:760-770.

Grasso M, Mazzini L, Schieppati M (1996) Muscle relaxation in Parkinson's disease: a reaction time study. Mov Disord 11:411-420.

Hanes DP, Carpenter RH (1999) Countermanding saccades in humans. Vision Res 39:2777-2791.

Hanes DP, Schall JD (1995) Countermanding saccades in macaque. Vis Neurosci 12:929-937.

Irlbacher K, Voss M, Meyer B-U, Rothwell JC (2006) Influence of ipsilateral transcranial magnetic stimulation on the triphasic EMG pattern accompanying fast ballistic movements in humans. J Physiol 574:917928.

Johansson H, Sjölander P, Sojka P (1986) Actions on gamma-motoneurones elicited by electrical stimulation of joint afferent fibres in the hind limb of the cat. J Physiol 375:137-152.

Kato K, Vogt T, Kanosue K (2019) Brain activity underlying muscle relaxation. Front Physiol 10:1457.

Kudo K, Ohtsuki T (1998) Functional modification of agonist-antagonist electromyographic activity for rapid movement inhibition. Exp Brain Res 122:23-30.

Kunesch E, Schnitzler A, Tyercha C, Knecht S, Stelmach G (1995) Altered force release control in Parkinson's disease. Behav Brain Res 67:43-49.

Labyt E, Cassim F, Devos D, Bourriez J-L, Destée A, Guieu J-D, Defebvre L, Derambure P (2005) Abnormal cortical mechanisms in voluntary muscle relaxation in de novo parkinsonian patients. J Clin Neurophysiol 22:192203.

Lappin JS, Eriksen CW (1966) Use of a delayed signal to stop a visual reaction-time response. J Exp Psychol 72:805-811.
Livesey EJ, Livesey DJ (2016) Validation of a Bayesian adaptive estimation technique in the stop-signal task. PLoS One 11:e0165525.

Logan GD (1994) On the ability to inhibit thought and action: a users' guide to the stop signal paradigm. In: Inhibitory processes in attention, memory, and language (Carr TH, Dagenbach D, eds), pp 189-239. San Diego: Academic.

Logan GD, Cowan WB (1984) On the ability to inhibit thought and action: a theory of an act of control. Psychol Rev 91:295-327.

Logan GD, Irwin DE (2000) Don't look! Don't touch! Inhibitory control of eye and hand movements. Psychon Bull Rev 7:107-112.

Logan GD, Cowan WB, Davis KA (1984) On the ability to inhibit simple and choice reaction time responses: a model and a method. J Exp Psychol Hum Percept Perform 10:276-291.

Logan GD, Schachar RJ, Tannock R (1997) Impulsivity and inhibitory control. Psychol Sci 8:60-64.

McGarry T, Franks IM (1997) A horse race between independent processes: evidence for a phantom point of no return in preparation of a speeded motor response. J Exp Psychol Hum Percept Perform 23: 1533-1542.

McGarry T, Inglis JT, Franks IM (2000) Against a final ballistic process in the control of voluntary action: evidence using the Hoffmann reflex. Motor Control 4:469-485.

Mena-Segovia J, Bolam JP (2017) Rethinking the pedunculopontine nucleus: from cellular organization to function. Neuron 94:7-18.

Mirabella G, Pani P, Paré M, Ferraina S (2006) Inhibitory control of reaching movements in humans. Exp Brain Res 174:240-255.

Motawar B, Hur P, Stinear J, Seo NJ (2012) Contribution of intracortical inhibition in voluntary muscle relaxation. Exp Brain Res 221:299308.

Oga T, Honda M, Toma K, Murase N, Okada T, Hanakawa T, Sawamoto N, Nagamine T, Konishi J, Fukuyama H, Kaji R, Shibasaki H (2002) Abnormal cortical mechanisms of voluntary muscle relaxation in patients with writer's cramp: an fMRI study. Brain 125:895-903.

Osman A, Kornblum S, Meyer DE (1986) The point of no return in choice reaction time: controlled and ballistic stages of response preparation. J Exp Psychol Hum Percept Perform 12:243-258.

Osu R, Gomi H (1999) Multijoint muscle regulation mechanisms examined by measured human arm stiffness and EMG signals. J Neurophysiol 81:1458-1468.

Pope PA, Holton A, Hassan S, Kourtis D, Praamstra P (2007) Cortical control of muscle relaxation: a lateralized readiness potential (LRP) investigation. Clin Neurophysiol 118:1044-1052.

Prins N, Kingdom FAA (2018) Applying the model-comparison approach to test specific research hypotheses in psychophysical research using the Palamedes toolbox. Front Psychol 9:1250.

Rothwell JC, Higuchi K, Obeso JA (1998) The offset cortical potential: an electrical correlate of movement inhibition in man. Mov Disord 13:330335.

Schall JD, Palmeri TJ, Logan GD (2017) Models of inhibitory control. Philos Trans R Soc Lond B Biol Sci 372:20160193.

Seo NJ, Rymer WZ, Kamper DG (2009) Delays in grip initiation and termination in persons with stroke: effects of arm support and active muscle stretch exercise. J Neurophysiol 101:3108-3115.

Serrien B, Baeyens J-P (2017) The proximal-to-distal sequence in upperlimb motions on multiple levels and time scales. Hum Mov Sci 55:156171.

Spraker MB, Corcos DM, Vaillancourt DE (2009) Cortical and subcortical mechanisms for precisely controlled force generation and force relaxation. Cereb Cortex 19:2640-2650.

Takakusaki K (2017) Functional neuroanatomy for posture and gait control. J Mov Disord 10:1-17.

Terada K, Ikeda A, Nagamine T, Shibasaki H (1995) Movement-related cortical potentials associated with voluntary muscle relaxation. Electroencephalogr Clin Neurophysiol 95:335-345.

Toma K, Honda M, Hanakawa T, Okada T, Fukuyama H, Ikeda A, Nishizawa S, Konishi J, Shibasaki H (1999) Activities of the primary and supplementary motor areas increase in preparation and execution of voluntary muscle relaxation: an event-related fMRI study. J Neurosci 19:3527-3534

Toma K, Nagamine T, Yazawa S, Terada K, Ikeda A, Honda M, Oga T, Shibasaki H (2000) Desynchronization and synchronization of central 
20-Hz rhythms associated with voluntary muscle relaxation: a magnetoencephalographic study. Exp Brain Res 134:417-425.

van den Wildenberg WPM, Burle B, Vidal F, van der Molen MW, Ridderinkhof KR, Hasbroucq T (2010) Mechanisms and dynamics of cortical motor inhibition in the stop-signal paradigm: a TMS study. J Cogn Neurosci 22:225-239.

Verbruggen F, Logan GD (2008) Response inhibition in the stop-signal paradigm. Trends Cogn Sci 12:418-424.

Verbruggen F, Logan GD (2009) Models of response inhibition in the stop-signal and stop-change paradigms. Neurosci Biobehav Rev 33: 647-661.

Verbruggen F, Aron AR, Band GP, Beste C, Bissett PG, Brockett AT, Brown JW, Chamberlain SR, Chambers CD, Colonius H, Colzato LS, Corneil
BD, Coxon JP, Dupuis A, Eagle DM, Garavan H, Greenhouse I, Heathcote A, Huster RJ, Jahfari S, et al. (2019) A consensus guide to capturing the ability to inhibit actions and impulsive behaviors in the stopsignal task. Elife 8:e46323.

Williams BR, Ponesse JS, Schachar RJ, Logan GD, Tannock R (1999) Development of inhibitory control across the life span. Dev Psychol 35:205-213.

Xue G, Aron AR, Poldrack RA (2008) Common neural substrates for inhibition of spoken and manual responses. Cereb Cortex 18:1923-1932.

Yazawa S, Ikeda A, Kaji R, Terada K, Nagamine T, Toma K, Kubori T, Kimura J, Shibasakil H (1999) Abnormal cortical processing of voluntary muscle relaxation in patients with focal hand dystonia studied by movement-related potentials. Brain 122:1357-1366. 